\title{
ESCUELAS PARA NIÑOS Y ESCUELAS PARA NIÑAS EN EL TRIENIO LIBERAL*
}

\section{SCHOOLS FOR BOYS AND SCHOOLS FOR GIRLS DURING LIBERAL TRIENNIUM}

\author{
Pilar García Trobat \\ Universitat de València
}

\begin{abstract}
SUMARIO: I. INTRODUCCIÓN.- II. CONSTITUCIÓN Y DESARROLLO NORMATIVO.- 2.1. Años de Cádiz.- 2.2. Trienio liberal.- III. LA INSTRUCCIÓN PÚBLICA AL SERVICIO DE LA CONSTITUCIÓN.- 3.1. Formación de ciudadanos.3.2. La instrucción política no es cosa de niñas.- IV. MAESTROS Y MAESTRAS.4.1. Maestros de primeras letras.- 4.2. Las maestras de niñas o de costura.- V. BUSCANDO DOTACIÓN.- VI. CONCLUSIÓN
\end{abstract}

Resumen: Durante el trienio liberal se aprobó la primera ley de instrucción pública en España y se ensayó, de forma interina, el proyecto de reglamento general de las escuelas de primeras letras. Las enseñanzas van dirigidas a que los niños, como futuros ciudadanos, afiancen el sistema liberal y las niñas atiendan el hogar y la familia. La escasez de fondos públicos y el breve periodo de tiempo en que la ley estuvo vigente hicieron fracasar la reforma, que no volverá a tenerse en cuenta una vez consolidado el sistema constitucional, como sí ocurriera con otras leyes del Trienio.

Abstract: During the Liberal Triennium, the first law of public instruction is approved in Spain, and the project of general regulations of primary schools is rehearsed on an interim basis. The education is directed to boys, as future citizens, must strengthen the liberal system while girls must attend home and family. The reform failed due to the shortage of public funds, and the short time the law was in force. After that attempt, this legal initiative would not be considered again with the consolidated constitutional system, unlike other projects of the triennium.

Palabras clave: Instrucción Pública, Constitución, Niñas, Niños, Maestro, Maestra, Trienio Liberal, Fondos Públicos.

Key Words: Public Instruction, Constitution, Boys, Girls, Male Teacher, Female Teacher, Liberal Triennium, Public Funds.

\section{INTRODUCCIÓN}

La transformación política de la sociedad pretendida por los liberales requería de un nuevo plan de estudios que acercara la lectura y la escritura a todos los niños a la par que los adoctrinara politicamente. La reforma de la instrucción pública debía ser prioritaria para que sus ideas fructificaran. No era nueva la preocupación por el estado de ignorancia y superstición en que se encontraba la mayor parte de los españoles. Los ilustrados ya la habian señalado 
e introducido las primeras medidas. Pero los liberales dan un paso más y conciben la enseñanza como instrumento para conformar la opinión en favor de la Constitución o, en palabras de Romero Alpuente, como "arma única con que se defiende un Estado liberal". ${ }^{1}$ De ella dependia "la consolidación del sistema constitucional". ${ }^{2}$ Las Cortes tenían que "echar los cimientos de la educación pública en que se libra la suerte futura del Estado". ${ }^{3}$ Sólo cuando todas las clases de la sociedad se ilustrasen, y conociesen sus deberes y sus derechos, se afianzarian las nuevas instituciones y se acabarian las reacciones politicas. ${ }^{4}$ En este sentido, no es extraño que la libertad de imprenta política se consagre en la Constitución de 1812 en el título referido a la instrucción pública. ${ }^{5}$

Durante la etapa gaditana y el Trienio liberal se hicieron grandes esfuerzos por establecer en todos los pueblos de la monarquía escuelas de primeras letras dotadas de maestros preparados y adictos a la Constitución y regirlas bajo el mismo método de enseñanza. Cuando el sistema liberal se instale definitivamente desaparecerá de las constituciones el título referido a la instrucción pública y no se repondrá, como ocurriera con otras reformas, la ley de instrucción pública que se aprobara en 1821.6

\section{CONSTITUCIÓN Y DESARROLLO NORMATIVO}

\subsection{Años de Cádiz}

En plena guerra de independencia la Junta Central se encargó de redactar unas "Bases para la formación de un plan general de instrucción pública". En la conocida "Consulta al país", se demandaron propuestas de "reformas necesarias en el sistema de instrucción y educación pública" para estudiarlas en las Cortes una vez se hubieran reunido, y reunidas éstas, en sus primeras sesiones se expresaron los deseos de llevar a cabo el arreglo de dicho ramo. ${ }^{7}$ El 19 de

* Este trabajo forma parte del proyecto de investigación I+D DER2016-78166-R.

1 Pilar García Trobat, La Constitución de 1812 y la educación politica, Congreso de los diputados, Madrid, 2010; Juan Romero Alpuente, Discurso sobre la urgentísima necesidad de Cortes extraordinarias, Madrid, Imprenta calle de bordadores, 1820, p. 29. Para los liberales, herederos de los ilustrados, la prosperidad de los pueblos dependía de la educación pública, Mariano Peset, "La enseñanza del Derecho y la legislación sobre Universidades, durante el reinado de Fernando VII" (1808-1833), Anuario de Historia del Derecho Español, 38(1968), 229-375, p. 249.

2 Diario de sesiones, núm. 116, 23 de junio de 1821, p. 2420.

3 Diario de sesiones, núm. 16, 20 de julio de 1820, p. 218. Aunque por enseñanza se entendía la parte literaria y por educación la moral, se refieren indistintamente a educación o enseñanza pública.

4 El Universal, núm. 236, 24 de agosto de 1822, p. 4.

5 Pilar García Trobat, "La libertad de imprenta, aliada de la revolución", en Pilar García Trobat y Remedio Sánchez Ferriz (coords.), El legado de las Cortes de Cádiz, Tirant lo Blanch, 2011, 285334.

6 Reglamento general de instrucción pública decretado por las Cortes en 29 de junio de 1821, Madrid, 1821.

7 "Bases para la formación de un plan general de instrucción pública", en edición de Cándido Nocedal, Obras publicadas e inéditas, BAE, Madrid, 1858, I, 268-276 y Miguel Artola, Gaspar Merchor Jovellanos, Obras publicadas e inéditas, BAE, 5 vols., Madrid, 1951-1956,1, pp. 268-276; Real Decreto por el que el Rey encarga a la Junta Suprema gubernativa que restableza y convoque 
noviembre de 1810 el maestro Antonio Pascual Castellanos remitía a las Cortes una "Memoria sobre la erección de escuelas de primeras letras" que se mandaba tener presente para cuando se formase la comisión encargada. A partir de entonces numerosas propuestas, muchas anónimas, trataron de aportar ideas nuevas. ${ }^{8}$ El 9 de diciembre de 1810 el diputado Espiga y Gadea pedía que se nombrara, entre otras, una comisión que formara el nuevo plan de educación e instrucción pública. ${ }^{9}$ Vista su proposición, aunque se consideró necesario establecer previamente las bases de la Constitución para tratar después las reformas de los ramos particulares, se acordó nombrar una comisión que planificara el número y objeto de las comisiones que convenía organizar.

El 9 de abril dicha comisión presentó el reglamento para la formación de las cinco comisiones que consideraba más necesarias. Junto a las de legislación civil, legislación criminal, legislación mercantil y sistema de hacienda, se establecía la comisión de instrucción y educación pública cuyo objeto sería "presentar un plan de enseñanza y de moral, en que la juventud adquiera todos los conocimientos necesarios para que la Iglesia tenga dignos ministros, el gobierno sabios magistrados, los ejércitos generales esforzados y virtuosos y toda la nación honrados e ilustrados ciudadanos." Solo unos días después el diputado Pelegrín proponía dejar el plan general de estudios para más adelante y que la comisión que se acababa de formar se encargase de momento de las escuelas de primeras letras y de los medios para dotarlas competentemente porque su "falta ha causado muchos perjuicios a la ilustración, y si no se remedia, son inútiles todos los planes que se discurran para enseñar a los hombres el camino de la virtud, porque no habrá maestros capaces de llevar a efecto dichos planes". Pero Espiga argumentó que al tiempo que formase el plan general, no se descuidaría la primera enseñanza ni la dotación de los maestros y los arbitrios de donde obterner los fondos. ${ }^{10}$ Se adelantaba uno de los mayores escollos con los que tropezaria el afán de esta reforma, la falta de fondos.

La Constitución de 1812 dedicaba todo un título, el IX, a la instrucción pública. Lo hacía precisamente a continuación del referido a la fuerza militar. Tenía sentido: los soldados y los maestros eran necesarios para sostener el Estado; los unos mantendrían el nuevo orden con las armas, los otros mediante la educación. En un capítulo único, compuesto por seis artículos, establecía las

a las Cortes para que debatan sobre los importantes trabajos y planes aconsejados por la propia Junta así como la reforma de la Administración, Gaceta del Gobierno, núm. 34, 5 de junio de 1809, pp. 566-568.

8 Diario de sesiones, núm. 54, 19 de noviembre de 1810, p. 113. Alguna de las propuestas de Castellanos en El Duende de los Cafées, lunes 20 de septiembre de 1813, pp. 219-220. Folletos y manuscritos de particulares sobre el arreglo de la enseñanza de primeras letras pueden encontrarse en el Archivo del Congreso de los diputados.

9 Propuesta de Espiga y Gadea: "habiendo sido convocadas las Cortes generales y extraordinarias no solo para formar una Constitución sino también para reformar nuestra legislación y conteniendo esta diversas partes que exigen diferentes comisiones, pido que se nombre una para reformar la legislación civil, otra para la criminal, otra para el sistema de Hacienda, otra para el comercio y otra para un plan de educación e instrucción pública", Diario de sesiones, núm. 74, 9 de diciembre de 1810, p. 153.

10 Diario de sesiones, 5 de febrero de 1811, núm. 132, 503; Sobre comisiones, Diario de sesiones, 9 de abril de 1811, núm. 192, p. 850, art. 10; Indicación del diputado Pelegrín, Diario de sesiones, 17 de abril de 1811, núm. 198, p. 884. 
líneas básicas que debían informar el plan a diseñar por la comisión. Aquellas bases las había adelantado el discurso preliminar del proyecto de Constitución: además de gratuita "debía ser general y uniforme, como generales y uniformes eran la religión y las leyes de la Monarquía española". ${ }^{11}$ Para que pudiera llegar a todos, para que fuera universal, la Carta Magna prescribia que en todos los pueblos de la monarquía debian establecerse escuelas públicas de primeras letras donde aprendieran los niños a leer, escribir, contar así como los dogmas de la religión y de la revolución (art. 366) dejando su inspección a una dirección general de estudios dependiente del gobierno (art. 370).

Siguiendo la linea de las reformas ilustradas, la enseñanza de las primeras letras no se configuraba como un derecho de los españoles sino como una obligación del Estado. En estos primeros momentos solo se trataba de una aspiración porque ni el plan de estudios estaba aprobado, ni la dirección de estudios nombrada, ni mucho menos había escuelas suficientes para todos los niños, ni determinados los fondos para dotar a tantos maestros. ${ }^{12}$ Hay que recordar además que en estos momentos estaban en guerra y llevar a la práctica estas reformas aunque necesarias no eran lo más urgente.

No fueron las únicas referencias que la Constitución hizo a la enseñanza primaria. En el artículo 321.5 dejaba al cuidado de los ayuntamientos todas las escuelas que se pagasen de fondos del común y en el 335.8 encargaba a las diputaciones provinciales "promover la educación de la juventud conforme a los planes aprobados." La Intrucción para el gobierno económico-político de las provincias, decretada el 23 de junio de 1813, desarrollaba estos preceptos constitucionales. El art. 14 del cap. 1 establecía que el ayuntamiento cuidaría de todas las escuelas públicas de primeras letras vigilando que los maestros cumplieran con las enseñanzas previstas en el art. 366 de la Constitución y dotándolos convenientemente de los fondos del común o en su defecto de los que la diputación acordase con las formalidades que disponía el art. 322 de la Constitución. Por su parte, la diputación según el artículo 12 del cap. 2 de la misma instrucción debía asegurarse de que los ayuntamientos establecieran escuelas suficientes y pagaran convenientemente a los maestros. Mientras no se formase la dirección general de estudios, la diputación provincial también quedaba encargada de realizar los exámenes de los maestros públicos y de expedirles el título gratuitamente para que pudieran ejercer en cualquier pueblo de su provincia. ${ }^{13}$

11 Pilar García Trobat, "Enseñando a leer, escribir, contar y la Constitución”, Anuario de Historia del derecho español, LXXXXI (2011), 521-540.

12 Sobre la falta de escuelas y maestros, en 1808 el intendente de Valencia informaba: "Las escuelas establecidas en nuestro Reyno encontraremos que su numero es muy inferior la que se necesita para educar cómodamente a los infinitos niños que hierven en los lugares; a más padres ignorantes, ayuntamientos compuestos por la mayor parte de gentes que ni ahún saven leer descuidan la observancia de las severas y repetidas órdenes de su Magestad sobre la asistencia de los niños a la escuela... Pero si todos enviaran sus hijos a las escuelas públicas como deviera ser no bastarian aun en nuestra ciudad ni los edificios ni los hombres destinados para dirigir la enseñanza". Expediente sobre la proposición hecha por Francisco Javier Aspiroz, intentente del reino de Valencia sobre la instrucción y mejora del método de educación y enseñanza en las escuelas de primeras letras, Archivo Histórico Nacional, sección Consejos, legajo 12004, exp. 56.

13 Decreto CCLXIX de 23 de junio de 1813, Instrucción para el gobierno económico-político de las provincias, Colección de los decretos y órdenes que han expedido las Cortes generales $y$ 
A primeros de octubre de 1813, las Cortes nombraron la comisión de Instrucción Pública que debía desarrollar las bases establecidas en la Constitución. ${ }^{14}$ Entre tanto, la Regencia que también prestaría atención a este ramo, procurará recabar información sobre el estado de todos los establecimientos de instrucción ${ }^{15}$ y además encargará un informe a una junta presidida por Quintana, que se presentaría a las Cortes el 29 de octubre de 1813 y que influiría notablemente en el proyecto de plan de estudios de la comisión de las Cortes. ${ }^{16} \mathrm{El}$ último día de esta legislatura el diputado Gordoa anunciaba estar terminado el plan. Vargas Ponce propuso entonces su impresión inmediata para ir avanzando. Pero no podía ser. El proyecto debía leerse en el Congreso antes de procederse a su impresión. Había que esperar hasta que las Cortes volvieran a abrirse. ${ }^{17}$

El 17 de abril de 1814 Martínez de la Rosa leyó en las Cortes el dictamen de la comisión y el proyecto de decreto que, nuevamente a petición de Vargas Ponce, se mandó imprimir con el propósito de comenzar a debatirlo ocho días después de repartido entre los diputados ${ }^{18}$. Aunque se imprimió, se hizo -como apuntaría años más tarde el mismo De la Rosa- "sin esperanzas de que se verificara la discusión por la crisis que ya amenazaba". ${ }^{19}$ Efectivamente no quedó tiempo para su discusión y aprobación. La vuelta de Fernando VII de su cautiverio significó la vuelta al antiguo régimen y a los programas de estudios anteriores.

extraordinarias desde 24 de febrero de 1813 hasta 14 de septiembre del mismo año, Cádiz, imprenta nacional, 1813, 105-126, citas en pp. 108-109 y 116.

14 Diario de sesiones, núm.1, 1 de octubre de 1813 p. 10: Eugenio de la Peña, José Miguel Gordoa, Andrés Navarro, José Joaquín Olmedo y Francisco Martínez de la Rosa; el día 10 se añadía a García Page y Clemencín, Diario de sesiones, núm. 11, p. 103; el día 1 de noviembre a Feliú y Mintegui, Diario de sesiones, núm. 34, p. 187. El 1 de marzo de 1814 habrá una nueva composición de la comisión: Obispo de Pamplona, Gabriel Ugarte y Alegría, José Domingo Mintegui, Francisco Martínez de la Rosa, Ignacio Ramón de Roda, Francisco Javier Caro, Joaquín Palacín, Salvador Samartín, Pedro Diez Garcia, Diario de sesiones, núm. 1, 1 de marzo de 1814, p. 8.

15 Circular expedida por la Regencia del reino el 16 de abril de 1813.

16 En Diario de sesiones, 29 de octubre de 1813, núm. 30, p. 173 se recogía: "a la comisión de Instrucción pública se mandó pasar un plan de bases para el mismo objeto, juntamente con un discurso en que se expresan los motivos fundamentales que ha habido para proponerlas, que remite el encargado de la Secretaría de la Gobernación de la Península, formado por una junta nombrada por el gobierno de personas de su confianza y fueron D. Martín González Navas, D. José de Vargas y Ponce, D. Manuel José Quintana, D. Eugenio Tapia, D. Diego Clemencín y D. Ramón de la Cuadra, cuyos trabajos han merecio la aprobación de S.M." La memoria presentada por el secretario del despacho de la gobernación de la península e islas adyacentes, decía presentado el informe antes del día 2 de octubre, Apéndice segundo al núm. 2, 2 de octubre de 1813, p. 25. Dicho informe puede verse en "Informe de la junta creada por la regencia para proponer los medios de proceder al arreglo de los diversos ramos de instrucción pública", en Manuel Quintana, Obras completas, BAE, edición de A. Ferrer del Río, Madrid, 1946, pp. 175-191. Sobre Quintana y su informe, véase, Albert Derozier, Manuel José Quintana y el nacimiento del liberalismo en España, traducido por Manuel Moya, Ediciones Turner, Madrid, 1978, pp.703-704.

17 Diario de sesiones, 19 de febrero de 1814, núm. 106, 495.

18 Diario de sesiones, 17 de abril de 1814, núm. 57, p. 264. Se publicaria como Dictamen y proyecto de Decreto sobre el arreglo general de la enseñanza pública, presentados a las Cortes por su comisión de instrucción pública y mandados imprimir por orden de la misma, s.1., s.a. E1 dictamen es obra fundamentalmente de Gordoa según Albert Derozier, Manuel José Quintana y el nacimiento del liberalismo, op. cit., p. 705.

19 Diario de sesiones, 20 de julio de 1820, p. 210. 


\subsection{Trienio liberal}

El levantamiento de Riego permitió la aprobación de la reforma liberal proyectada en Cádiz, aunque su vigencia sería muy breve. Instaladas las Cortes, el 10 de julio se nombró una nueva comisión de instrucción pública que repartió impreso el proyecto de 1814 a los nuevos diputados. ${ }^{20}$ Algunos de ellos consideraron entonces que no habia tanta prisa porque respecto de las universidades se había adoptado provisionalmente el plan de 1807. De nuevo el diputado Vargas Ponce sería quien señalase la urgencia del plan respecto a la primera enseñaza. ${ }^{21}$

Por fin en la sesión extraordinaria de 19 de octubre de 1820 se leyó por tercera vez y se publicó en el Diario de sesiones un nuevo proyecto de decreto con algunas modificaciones respecto del de $1814 .{ }^{22}$ Al día siguiente comenzó el debate que, no obstante, quedó suspendido el 21 de octubre de $1820^{23}$ porque "asuntos más urgentes aunque no más interesantes ocuparon con preferencia la atención de las Cortes". Al acabar la legislatura unos días más tarde, el 9 de noviembre, habían quedado aprobadas la primera y segunda enseñanza -hasta el artículo 31.

El 20 de febrero de 1821 dio comienzo una nueva legislatura y el 19 de marzo se retomó el debate comenzado en la anterior. Había transcurrido tiempo suficiente para que arreciaran las críticas contra el plan proyectado. Entre otras cosas se censuraba la postergación de las escuelas de primeras letras en un plan que calificaban de "ideal y gigantesco" y que daba preferencia al establecimiento de una Universidad Central en la corte. El diputado Tapia propuso entonces que estando aprobada la parte del plan relativa a la primera enseñanza, se pasase al gobierno para que la pusiera en ejecución, sin necesidad de que el plan general estuviera acabado. Algunos diputados temieron que el propósito fuera retrasar una vez más la aprobación de un plan general. García Page salió en su defensa:

¡Desgraciado plan de instrucción pública, y desgraciada especie humana, que siempre tiene que superar dificultades de toda clase cuando se propone algún proyecto en bien de la humanidad! [...] En la legislatura del año 1814, y aún en la del 13, ya existía este plan de enseñanza; pero por más esfuerzos que hicimos los individuos de la comisión de instrucción pública no pudimos conseguir que se presentara a discusión. En la legislatura pasada tampoco pudo concluirse la discusión de todo el proyecto... Me opongo a que se suspenda la discusión del plan general. ${ }^{24}$

Se pidió dictamen a la comisión de instrucción pública que se mostró a favor de continuar con la discusión y de que una vez aprobado el plan general, se

20 La comisión estaba integrada por Muñoz Torrero, Vargas Ponce, Tapia, Navas, Martínez de la Rosa, Garcia Page, Andrés Navarro, Cortés y Martel. A ellos se agregaron los diputados Rodríguez, Queipo, Rojas Clemente y Janer y de fuera, Quintana, Gutiérrez, Cuadra y La Gasca, Diario de sesiones, núm. 16, 20 de julio de 1820.

21 Diario de sesiones, núm. 19, 23 de julio de 1820, p. 249.

22 El 23 de septiembre se leería por primera vez el proyecto de decreto sin imprimir, sesión extraordinaria, núm. 81, p. 1192; por tercera vez 19 de octubre núm. 107, pp. 1788-1794.

23 Diario de sesiones, núm. 108, 20 de octubre de 1820, p. 1810 y núm. 109, 21 de octubre de 1820 , p. 1834.

24 El debate en Diario de sesiones, núm. 22, 19 de marzo de 1821, pp. 560-562. La cita de Garcia Page en p. 561. Proposición de Tapia en p. 560. 
encargara al gobierno la ejecucion por partes, empezando por la primera enseñanza -cuyo establecimiento era el más urgente- "aprovechando para él todos los medios y auxilios que los pueblos mismos puedan proporcionar, y los demás que estén a su alcance, contando siempre con la cooperación de las Cortes para todo lo que no esté en la esfera constitucional de sus atribuciones". De hecho ya estaba previsto en los arts. 132 y 133 del proyecto. ${ }^{25}$

El Reglamento general de instrucción pública finalmente se aprobaría el 29 de junio de $1821 .{ }^{26}$ Pocos artículos dedicaba a la primera enseñanza, lo dejaba a reglamentos particulares. La dirección general de estudios, instalada el 6 de agosto de 1821, remitiría el 19 de marzo de 1822 a las Cortes, a través del secretario de despacho de la gobernación de la península, un oficio en el que incluía una exposición sobre el estado de la enseñanza pública, un proyecto de reglamento general de primera enseñanza junto a "otro plan metódico de la misma con otros varios documentos" que las Cortes mandaron imprimir. La comisión de instrucción de estudios con algunos retoques haría suyo el proyecto de reglamento de la dirección general y se mandó imprimir. ${ }^{27}$ El 29 de junio, sin debatirlo, las Cortes autorizaron al gobierno a ponerlo en ejecución, "hasta la próxima legislatura en que deberán discutirse a propuesta de la comisión". ${ }^{28} \mathrm{E} 1$ gobierno envía el reglamento interino a los jefes politicos mediante circular de 30 de septiembre de 1822 ordenando que se aplicara. La diputación valenciana, por ejemplo, el 14 de octubre acordó "repartir entre los señores vocales los exemplares de la circular que acompañaba el señor jefe político con la real orden que previene poner en práctica el Proyecto de reglamento general de primera enseñanza y el traslado del mismo."29

\section{LA INSTRUCCIÓN PÚBLICA AL SERVICIO DE LA CONSTITUCIÓN}

\subsection{Formación de ciudadanos afectos}

El discurso preliminar del proyecto de Constitución adelantaba los objetivos de la instrucción pública. Se trataba de formar "verdaderos españoles, hombres de bien y amantes de su patria" y para ello resultaba necesario que no quedase en manos de personas "imbuidas de opiniones o principios equibocados, que tal

25 Petición dictamen, Diario de sesiones, núm. 57, 25 de abril de 1821, p. 1262; Dictamen de la comisión de instrucción pública, en núm. 60, 28 de abril, p. 1319-1320.

26 Imprenta nacional, Madrid, 1821.

27 Proyecto de la dirección general de estudios, Diario de sesiones, núm. 28, 19 de marzo de 1822, p. 419. Las Cortes mandan imprimir el dictamen de la comisión, Diario de sesiones, núm. 153, 22 de junio de 1822, p. 2070.

28 Gaceta de Madrid, núm. 188, 30 de junio de 1822, p. 1024.

29 Véase Alfredo Sáenz-Rico Urbina, La educación general en Cataluña durante el Trienio Constitucional (1820-1823), Universidad de Barcelona, 1973, p. 495 y Actas de la diputación de Valencia, 14 de octubre de 1822, p. 31, Archivo de la diputación de Valencia. También la diputación provincial de Chinchilla vería la circular en octubre, Gaceta de Madrid, núm. 344, de 24 de noviembre de 1822, pág. 1.734. El título completo del proyecto era Proyecto de reglamento general de primera enseñanza, que se ha de observar en todas las escuelas de primeras letras de la monarquiaa española. Aprobado interinamente por el gobierno a propuesta de la dirección general de estudios, conforme a lo acordado por las Cortes en 29 de junio próximo, Madrid, 1822. Nos referiremos al mismo como Reglamento interino. 
vez establecerian una funesta lucha de opiniones y doctrinas."30 La educación debía ser conforme a las ideas liberales, de ahí que el art. 366 prescribiera la enseñanza de la Constitución desde la infancia, en las escuelas de primeras letras.

El Estado asumía la obligación de que todos los niños pudieran acceder a la escuela pública no solo por lo dispuesto en el art. 366 sino también por cuanto que según el artículo 25.6 solo los que a partir de 1830 supieran leer y escribir podrían acceder a la ciudadanía. Esta medida que no se conocía en ninguna otra legislación extranjera fue aplaudida por quienes vieron en ella la intención de acabar con el analfabetismo, dado que animaría a los padres a enviar a sus hijos a la escuela. ${ }^{31}$ Pero, al no quedar sujeta a ninguna pena la falta de cumplimiento de los progenitores, la sola suspensión de unos derechos que no comprendian, no supuso una afluencia masiva a las aulas. ${ }^{32}$ Tampoco habria sido posible aunque hubieran querido. No había escuelas ni maestros para tantos. De ahí que hubo quien interpretó esta medida como una maniobra de los liberales para, de una parte, justificar la ignorancia de diputados y ministros y de otra, restringir a la larga el derecho al voto. El ejercicio de los derechos políticos, concedidos por la Constitución de una forma generosa, quedaría muy reducido al suspenderlo a partir de 1830 a la mayoría de los españoles que seguirian siendo analfabetos. ${ }^{33}$

En cualquier caso, el precepto jamás podría cumplirse si efectivamente el Estado no proveía a los niños de los medios necesarios. Quedaba obligado a instalar escuelas gratuitas donde pudieran aprender a leer y escribir con maestros preparados "porque si es muy justo que el que por omisión o indolencia no quiere aprender las primeras letras esté suspenso de los derechos de ciudadano, no lo es ciertamente el que, aun cuando quiera, no puede verificarlo por falta de medios." 34 El Estado se comprometía a que esta primera enseñanza

30 Actas de la diputación de Valencia, 14 de octubre de 1822, pp. 77-78, Archivo de la diputación de Valencia.

31 Ramón Salas, Lecciones de derecho público constitucional para las escuelas de España, 2 vols., Madrid, Imprenta del Censor, 1821, II, p. 53. También Blanco White felicitó la preocupación de las Cortes por alfabetizar a la población, aunque no vio claro que se limitaran los derechos de los españoles, El Español, enero-febrero de 1814, p. 8.

32 Hubo quien sugirió como medida más eficaz prohibirle la administración de sacramentos a quien no supiese leer y escribir, Sencillas reflexiones a varios artículos de la Constitución de la Monarquía española publicada en Cádiz a 19 de marzo de 1812. Por las que se prueba lo confusa, inútil y perjudicial que era a los pueblos, Madrid, por Burgos, 1814, pp. 38-39. Y quien, como Pascual Castellanos consideró que el castigo era tan justo que tampoco debería poder casarse, quien por desidia no aprendiese, El Duende de los Cafées, lunes 20 de septiembre de 1813, pp. 219.

33 Pilar García Trobat, "Españoles instruidos por la Constitucion", Revista de Derecho politico, 82 (sep.-dic. 2011, 319-350, pp. 342-343. En 1821 el jefe político de Guadalajara decía que "muchos pueblos de 15 a 20 vecinos, de los 520 de que consta aquella provincia, se verán expuestos a componerse para el tiempo que señala la Constitución de individuos que no gozarán los derechos de ciudadano, si no se establecen escuelas, o se tolera se dediquen a la enseñanza sujetos que no tengan el requisito de estar examinados", Memoria leida a las Cortes por el encargado del Despacho de la secretaría de gobernación de la península, apéndice segundo al núm. 7, 4 de marzo de 1821, pp. 85-105.

34 "La sociedad gaditana de amigos del hombre hace algunas observaciones sobre los medios de mejorar la enseñanza pública, fechado el 26 de septiembre de 1820, legajo 77, núm. 143, Archivo del Congreso de los Diputados. 
fuera gratuita y estuviera al alcance de cualquier niño. No significaba el reconocimiento de la enseñanza como un derecho. Tampoco se establecía como enseñanza obligatoria porque no habia recursos suficientes para mantener edificios ni maestros. Solo muestra la voluntad de alfabetizar a los menores al tiempo que aprendian los principios constitucionales; era por tanto una voluntad condicionada por el deseo de formar a los niños, futuros ciudadanos, adictos al sistema liberal.

La vinculación de la enseñanza con la idea de extender el conocimiento y beneficios de la carta magna quedó patente cuando una de las primeras medidas adoptadas por el gobierno provisional en mayo de 1820, al poco de jurar el rey la Constitución de 1812, fuese ordenar su enseñanza en iglesias, colegios de primeras letras, universidades y cualquier otro tipo de establecimiento de educación. Por real orden se decretaba que "en todas las escuelas de primeras letras y humanidades del reino se explicará por los maestros la Constitución de un modo claro y perceptible a la edad y comprensión de los niños, a quienes se familiarizará con la lectura, ejercitándolos en la del mismo código fundamental". 35 Ya lo prescribía la carta magna, era una de las bases que informaban la instrucción pública, pero después del fracaso de la primera etapa liberal se creyó necesario enmendar errores y dejar en manos de personas influyentes y en quienes el pueblo confiaba, la enseñanza de la carta magna, aun antes de aprobarse el plan de estudios. ${ }^{36}$ Los jefes politicos se encargaron de velar por el cumplimiento de la real orden. Ante las quejas de los ayuntamientos contra maestros por su falta de cumplimiento, el jefe político de Barcelona resolvió imponerles una multa de 5 libras advirtiéndoles que si reincidían se le doblaria la multa y se procedería contra ellos. ${ }^{37}$ El jefe político de Madrid multó a los ayuntamientos que desde 1820 habia habido en Fuencarral, a pagar "de su bolsillo dos dias del sobre prest de la tropa a razón de 5 reales diarios por plaza", por no haber hecho ninguna gestión a pesar de que el maestro no explicaba la Constitución. ${ }^{38}$

El proyecto de plan de estudios de 1820 en su art. 8 disponía que "en las escuelas, conforme al citado art. 366 de la Constitución, aprenderán los niños a leer y escribir correctamente y asimismo las reglas elementales de aritmética; un catecismo que comprenda brevemente los dogmas de la religión y las máximas de buena moral; y otro político, en que se expongan del mismo modo los derechos y obligaciones civiles". En el Reglamento de 1821 dicho artículo quedó reformado en el artículo 12- de la manera siguiente: "En estas escuelas, conforme al citado artículo 366 de la constitución, aprenderán los niños a leer y escribir

35 Real orden de 24 de abril de 1820 sobre que se explique la constitución por los curas párrocos y en los establecimientos de instrucción pública”, Colección de los decretos y reales órdenes que se han expedido o circulado por la secreatría del despacho de la gobernación de la península, correspondientes a los años 1820 y 1821, Madrid, Imprenta nacional, 1822, pp. 12-13, cita en p. 12.

36 Resultaba esencial implicar al clero, véase, la alocución del jefe político de la provincia de Valencia, Francisco Plasencia, llamando a los curas no solo a hacer triunfar las instituciones politicas "disipando temores maliciosamente sugeridos" sino a dirigir las conciencias de los fieles hacia los intereses del estado, Diario de Valencia, núm. 56, lunes 25 de febrero de 1822, pp. 222223.

37 Miscelánea de comercio, política y literatura, núm. 499, 11 de julio de 1821, p. 3.

38 Diario constitucional, politico y mercantil de Palma, núm. 81, 19 de septiembre de 1822. 
correctamente y asimismo las reglas elementales de aritmética y un catecismo que comprenda brevemente los dogmas de la religión, las máximas de buena moral y los derechos y obligaciones civiles". Aparentemente se trataba de una modificación sin importancia. Se sustituían los dos catecismos previstos en el proyecto por uno solo donde se explicara religión y obligaciones civiles conjuntamente. Esta enmienda se debió a la indicación del diputado Romero Alpuente para quien la Constitución claramente había dispuesto un solo catecismo porque el legislador entendió que "los deberes políticos estaban estrechamente enlazados con los religiosos." 39 El estudio de los principios de la religión tan penetrado en la tradición española podía ayudar a extender de forma más amable los principios de la Constitución si se mostraban interrelacionados.

La dirección de estudios en 1822 concretaba más. El catecismo que se adoptara, se debía hacer aprender a los niños de memoria y destinar "un dia a la semana para hacer una esplicacion clara y sencilla, así de la doctrina cristiana, como de las obligaciones civiles, teniendo siempre en consideracion la corta capacidad de los niños, para no confundirlos y ofuscarlos en vez de instruirlos". 40

Solo en este ambiente de exaltación politica puede entenderse la proposición del diputado González Alonso que pidió a las Cortes que acordaran: "1. Que llegado el caso de sancionarse el código penal y demás de nuestra legislación, se impriman en términos que los niños aprendan a leer por ellos, sin que esto embarace su instrucción en los principios de nuestra religón. 2. Que esta impresión se haga a coste y costas, cuidando los ayuntamientos constitucionales de exigir de los padres de familia que tengan facultades, el importe de los ejemplares para sus hijos y respecto de los que no las tengan, se suplirá por los fondos de beneficencia, de los cuales se proveerá asimismo a los maestros de primeras letras". ${ }^{41}$

No se determinó el catecismo que debían memorizar los niños. El secretario de gobernación hizo referencia en su memoria de 1813 a los de Miguel de Porrua de Sevilla y Jacobo Violan Romero de Ferrol. ${ }^{42}$ Pero el hecho de que se dispusiera que en las escuelas militares se explicara la Constitución según el Catecismo politico arreglado a la Constitución de la monarquia española, para la ilustración del pueblo, de la juventud y uso en las escuelas de primeras letras de D. J. C. , que se

39 Diario de Sesiones, sesión extraordinaria de 20 de octubre de 1820, núm. 108, p. 1811.

40 Esposicion sobre el estado de la enseñanza pública, hecha a las Cortes por la direccion general de estudios impresa de orden de las mismas, Madrid, imprenta de Alban y compañia, 1822.

41 Diario de sesiones, sesion extraordinaria de la noche del 9 de mayo de 1822, núm. 7. También recién aprobada la Constitución los maestros de primeras letras de Cádiz manifestaron sus deseos de hacer que los niños recitaran de memoria no solo la constitución sino también los códigos civil y penal, cuando se aprobaran "para que sus educandos, al paso que conozcan la dignidad del ciudadano que cumple el contexto de la ley, estudien y teman la degradación y castigo a que se hace acreedor el que lo quebrante", Diario de sesiones, 27 de junio de 1812 , p. 3.378. Véase Mariano Peset y Pilar García Trobat, "La Constitución de 1812 o cómo educar a un pueblo”, en Remedio Sánchez Ferriz y Mariano García Pechuán (coords.), La enseñanza de las Ideas constitucionales en España e Iberoamérica, Ene edicions, Valencia, 2001, 23-62, p. 34.

42 Jacobo Violán Romero, Catecismo politico o Breve explicación de las obligaciones civiles acomodada a la inteligencia de los niños según lo previera a los maestros la constitución de la monarquía, por el maestro de la escuela de Ferrol, Santiago, Manuel Antonio Rey, 1820. Sobre este maestro puede verse Alfredo Martín García, "La enseñanza de las primeras letras en El Ferrol de finales del Antigo Régimen”, Estudios humanísticos. Historia, 6 (2007), 169-194, pp. 176 ss. 
publicara en castellano y catalán así como sus numerosas reimpresiones nos indica que fue uno de los más utilizados. ${ }^{43}$ En la prensa se anuncia:

El autor que se ha propuesto en esta obra ilustrar al pueblo e instruir a la juventud en todos los esenciales beneficios que nos resultan del sagrado Código de nuestras leyes fundamentales, desempeña con perfección su objeto; explicando clara y concisamente por preguntas y respuestas, las significaciones de Constitución, nación española, ley, diferencia de español y ciudadano español, gobierno y sus modificaciones, cortes, etc. Es obra sumamente recomendable para el uso de las escuelas de primeras letras; porque acostumbrándose los niños a grabar en su mente, entre sus primeras indelebles ideas, éstas que han de formar su felicidad y la del estado, será imposible ya a ningún tirano astuto borrarlas de su entendimiento con sofísticas interpretaciones. ${ }^{44}$

\subsection{La instrucción política no es cosa de niñas}

La enseñanza de las primeras letras, ya lo hemos visto, principalmente se dirigió a extender el conocimiento de la Constitución entre quienes en unos años podian llegar a convertirse en ciudadanos y gozar de los derechos políticos. Dándoles a conocer los beneficios del nuevo sistema, desde su más tierna infancia, llegarian a confiar en las nuevas instituciones y defenderian los logros de la revolución. De ahí que la instrucción pública se concibiera solo para hombres, los únicos que podían acceder a la ciudadanía. La enseñanza de la mujer seguiría entendiéndose reducida al ámbito doméstico. El dictamen que precedia al proyecto presentado en 1814 así lo recogia:

Al concluir la Comisión el plan general de instrucción pública, no se ha olvidado de aquel sexo, que forma una parte preciosa de la sociedad; que puede contribuir en gran manera a la mejora de las costumbres y que apoderado casi exclusivamente de la educación del hombre en su niñez, tiene un gran influjo en la formación de sus primeros hábitos y lo sigue ejerciendo después en todas las edades de la vida humana. Pero la comisión ha considerado al mismo tiempo que su plan se reducía a la parte literaria de la educación, y no a la moral, principal objeto de la que debe darse a las mujeres. Tampoco pudo desatenderse de que este plan solo abraza la educación pública, y que cabalmente la que debe darse a las mujeres ha de ser doméstica y privada en cuanto sea posible, pues así lo exige el destino que tiene este sexo en la sociedad la cual se interesa principalmente en que haya buenas madres de familia. Pero como además de la educación doméstica de las mujeres, que necesariamente se ha de mejorar con el progreso de la instrucción nacional y el fomento de la riqueza pública, convenga que el Estado costee algunos establecimientos en que aprendan las niñas a leer y escribir, y las labores propias de su sexo, la Comisión opina que se debe encomendar al zelo de las Diputaciones provinciales el que

43 Gaceta de Madrid, núm. 78, del jueves, 11 de mayo de 1820, p. 530.

${ }^{44}$ Diario de Palma, núm. 60, miércoles 4 de noviembre de 1812, p. 264. 
propongan el número que deba haber de estos establecimientos, el paraje donde deban situarse, su dotación y forma. ${ }^{45}$

La preocupación por la educación de la mujer no era nueva. No era una cuestión liberal. Los ilustrados ya se habían interesado por ella. De hecho, las reformas liberales guardarán gran similitud con la legislación de Carlos III. "Como la educación de la juventud no se debe limitar a los varones, por necesitar las niñas también de enseñanza, como que han de ser madres de familia..." recogía una real cédula en 1768 en un sentido similar al texto anteriorme trascrito. ${ }^{46} \mathrm{Su}$ instrucción importaba en cuanto que como madre de familia tendría a su cargo a sus hijos menores. De ahí que el principal objeto de su educación fuera, según una real cédula de 1783, imprimir en las jóvenes "los principios de la religión, las buenas inclinaciones y hábitos virtuosos al mismo tiempo que se instruyen en la destreza de sus labores", aunque "si alguna de las muchachas quiere aprender a leer, tendrá igualmente la maestra obligación de enseñarla."47

Pero ciertamente entre las medidas ilustradas y las proyectadas por los liberales, una guerra, en la que la mujer había jugado un papel importante, había trastocado todo el orden social. Instaladas las Cortes en 1810 no se cuestionó la conveniencia de su participación e incluso de su instrucción en los principios políticos. En la discusión del proyecto de Constitución ya se vislumbra la postergación del sexo femenino a quien, negándosele su capacidad de poder ser

45 Dictamen y proyecto de decreto sobre el arreglo general de la enseñanza pública presentado a las Cortes por su comisión de Instrucción pública, pp. 19-20. De forma similar se expresaba Jovellanos: "La educación de las niñas, que es tan importante para la instrucción de esta preciosa mitad de la nación española, y que debe tener por objeto el formar buenas y virtuosas madres de familia, lo es mucho más tratándose de unir a esta instrucción la probidad de sus costumbres; de una y otra dependen las mejoras de la educación doméstica, así como las de esta primera educación tienen luego tan grande y conocido influjo en la educación literaria, moral y civil de la juventud. Por tanto meditará muy detenidamente la Junta los medios de erigir por todo el reino: $1 .^{\circ}$ escuelas gratuitas y generales para que las niñas pobres aprendan las primeras letras, los principios de la religión y las labores necesarias para ser buenas y recogidas madres de familia; 2. ${ }^{\circ}$ los de organizar colegios de niñas, donde las que pertenezcan a familias pudientes puedan recibir a su costa una educación más completa y esmerada", Bases para la formación de un plan general de instrucción pública (1809), Obras publicadas e inéditas, colección hecha e ilustrada por Cándido Nocedales, BAE, Madrid, 1858, I, 268-276, p. 270. Véase también Quintana en su informe: "No hemos hablado en esta exposición, ni dado lugar entre las bases, a la instrucción particular que debe proporcionarse a las mujeres, contentándonos con indicar que las diputaciones propongan en esta parte los establecimientos de enseñanza que convengan. La Junta entiende que, al contrario de la instrucción de los hombres, que conviene sea pública, la de las mujeres debe ser privada y doméstica; que su enseñanza tiene más relaciones con la educación que con la instrucción propiamente dicha; y que para determinar bases respecto de ella era necesario recurrir al examen y combinación de diferentes principios políticos y morales, y descender después a la consideración de intereses y respetos privados y de familia; que aunque de la mayor importancia, puesto que de su acertada disposición resulta la felicidad de uno y otro sexo, no eran por ahora de nuestra inspección, ni nos han sido encargados.”

46 Establecimiento de casa para la educación de niños y de las de enseñanza para niñas, Novisima Recopilación, Libro VIII, tít. 1, ley IX, real cedula de 14 de agosto de 1768.

47 "Las labores que las han de enseñar han de ser las que acostumbran; empezando por las más fáciles, como faxa, calceta, punto de red, dechado, dobladillo, costura; siguiendo después a coser más fino, bordar, hacer encaxes; y en otros ratos, que acomodará la maestra según su inteligencia, a hacer cofias o redecillas, sus borlas, bolsillos y diferentes puntos, cintas caseras de hilo, de hilaza de seda, galón, cintas de cofias y todo género de listoneria", Establecimiento de escuelas gratuitas en Madrid para la educación de niñas y su extensión a los demás pueblos, Novisima Recopilación, Libro VIII, tít. 1, ley X, real cédula de 11 de mayo de 1783, puntos 5 y 11. 
ciudadana, se equiparaba con los niños y aún con los locos. El diputado Leiva, entre otros diputados, coincidia en que "las mujeres no son electores ni elegibles, no lo son los niños y los que están desproveídos del ejercicio de la razón y tampoco los que estén suspendidos de los derechos de ciudadanía y los que lo han perdido" y el diputado Terrero señalaba lo absurdo de ampliar la ciudadanía a las castas americanas porque entonces "sería forzoso conceder a las mujeres con los derechos civiles los políticos y admitirlas en las juntas electorales y en las Cortes mismas. ${ }^{48}$ Para todos los diputados no había duda, la mujer no era ni podía ser ciudadana.

Después vendría la cuestión sobre la pertinencia de su presencia en los debates parlamentarios. En las Cortes gaditanas se aprobó su exclusión sin ningún debate. En el artículo 3 del reglamento para el gobierno interior de las Cortes -aprobado el 27 de noviembre de 1810- se disponía que "no se permitirá a las mugeres la entrada en ninguna de las galerias de la sala de sesiones" y sin embargo, "los hombres de todas clases podrán indistintamente asistir a ellas."49

Al iniciarse el trienio liberal parece haberse producido algún cambio. En las Cortes se abre el debate, que en Cádiz no hubo, sobre su presencia en las galerias. ${ }^{50}$ No parece sin embargo que hubiera una conciencia critica por parte de la mayoría de las mujeres, que sólo de manera puntual y a través de la prensa manifiestan su disconformidad en cuanto al papel que les reservaba el nuevo régimen. ${ }^{51}$ Sería el diputado Rovira quien pidió que se suprimiera la prohibición, bastaba con requerir la debida separación entre hombres y mujeres en las galerias. Opinaba que asistiendo las mujeres a los debates politicos se imbuirian de las ideas liberales que después imprimirian en sus hijos y la generación futura sería constitucional. Moscoso juzgaba que atentaba al espíritu de civilización y se igualaban a naciones orientales donde a la mujer por ideas politicas y religiosas se le negaba la asistencia a los actos públicos. Era necesario tener en cuenta a la mujer en esta lucha.

48 Leiva en Diario de sesiones, 14 de septiembre de 1811 , núm. 347, p. 1844. Terrero en Diario de Sesiones, 6 de septiembre de 1811, p. 1790.

49 Reglamento para el gobierno interior de las Cortes, Imprenta real, Cádiz, 1810, p. 3.

50 En la discusión del proyecto de reglamento para el gobierno interior de las Cortes, el diputado Rovira pretendió modificar parte del artículo 7, por el que se excluía a la mujer de la entrada en el congreso. Le apoyaron los diputados Moscoso, Romero Alpuente y Flórez Estrada, pero perdieron la votación por 85 contra 57. Diario de sesiones, 16 de marzo de 1821, núm. 19, pp. 498-500. El debate se trasladó a la prensa, véase, El Censor, n. 23, pp. 267-298 y n. 36, pp. $433-443$.

51 Llama la atención la publicación de un panfleto -que no he podido localizar- anunciado con el título "Representación histórica nominal, de la excma. señora viuda del general don Luis Lacy, martir por defender los derechos del pueblo español y otras beneméritas ciudadanas, solicitando que el soberano congreso acceda a su solicitud de tribuna en el salón de Cortes por los méritos que alegan desde 1521, contraidos por la heroína doña María Pacheco y Mendoza, viuda del general, también mártir Juan de Padilla, individuo de la grandeza; cuya preeminencia tienen axecutoria de antiguo las ciudadanas en la cámara de la ilustrada Francia”, El Constitucional. Correo general de Madrid, jueves 3 de mayo de 1821, P. 262. También El Espectador, martes 29 de mayo de 1821 , p. 180, recoge la misma publicación pero bajo el título El elogio a las mugeres osea representación histórica nominal de la Ecma. señora doña Emilia Duguermeus. Pero por lo que deja entrever el título no se refiere a una protesta por su exclusión en virtud de su sexo sino de su clase social. 
¿Qué cosa habrá más interesante que el que una madre de familia y una esposa conozcan los fundamentos de las leyes y las razones que ha habido para decretar aquéllas que establecen las reciprocas obligaciones y las mutuas relaciones de los individuos de su sexo con el otro y los principios de moral y conveniencia en que están fundadas? Supuesto que ellas han de ser las que, como directoras y apoyos de la tierna infancia, influyan directamente en sus primeras inclinaciones. ¿Por qué no se ha de encontrar una gran ventaja en que vengan a las cortes a oír las lecciones que con tanto fruto pueden después repetir a sus hijos, para formar en ellos ciudadanos virtuosos y amantes de las leyes de su patria? ¿Podremos olvidarnos de que las ideas que adquirimos en nuestros primeros años son casi generalmente las que determinan en el resto de la vida nuestra conducta y nuestras inclinaciones?... ¿por qué se ha de estorbar el medio de que nuestros hijos mamen con la leche los principios de obediencia y amor a estas mismas leyes, que hasta cierta edad solo pueden inspirarles aquellas personas encargadas por la misma naturaleza de su primera educación?

No sólo era importante tener en cuenta a la mujer como educadora de sus hijos sino también atendiendo sólo a su propia educación, “¿era acaso menos digna de interés que la instrucción de los hombres?" E1 diputado Romero Alpuente era de la misma opinión. Las mujeres iban a misa o al teatro como los hombres y nunca se había interpretado su presencia incompatible con el orden y el decoro. No sólo influían en los hijos sino que dominaban a los hombres. ${ }^{52}$ Flórez Estrada señaló que algunas mujeres acudian a las sesiones extraordinarias por la noche disfrazadas de hombres y de la misma manera lo harian, con esta prohibición, por la mañana. Pero el diputado Sancho, miembro de la comisión que presentó el proyecto, no estuvo de acuerdo. La principal cualidad de una mujer, decía, no consistía en que entendiese en los negocios públicos sino en que supiera criar y cuidar bien de sus hijos. Los que debían influir en la educación política de sus niños eran los hombres. Para Martel la única instrucción que debía darse a las mujeres era la doméstica y no era partidario de su asistencia en las discusiones públicas.

Para la mayoría de los diputados y de la opinión pública "la principal prenda o virtud de una señora no consiste en que entienda en los negocios públicos... sino en que sepa criar y cuidar bien sus hijos, y en no abandonar sus ocupaciones domésticas". ${ }^{53}$ De nuevo su exclusión quedó aprobada. Si en Cádiz las razones esgrimidas a través de la prensa eran los deseos de guardar el debido decoro y el orden en el Congreso, ahora se alegaba que aunque las mujeres pudieran respetar el silencio exigido en los reglamentos del Congreso, asistir a

52 Es bueno decía en otra ocasión Romero Alpuente que "sepan los hombres, es bueno que también lo sepan las señoras: ellas están tan interesadas como aquellos en la felicidad de la patria, y esta felicidad consiste en el cumplimiento de la Constitución, y de aquí se infiere la necesidad de conocer todo lo que ella promete al pueblo español," El Indicador, núm. 185, 5 noviembre 1822 , p. 878.

53 Idéntica preocupación mostraron los absolutistas tras la restauración del absolutismo. La prensa más afin insistió en la necesidad de su educación, pero siempre en atención a su destino en la sociedad: "toda nación que desee ser feliz, debe adoptar necesariamente un plan de educación para el sexo femenino, estableciendo colegios en donde principalmente se les enseñe la religión por principios, las obligaciones de una buena esposa, las de una madre de familias, el arte de educar los hijos...", La Atalaya de la Mancha en Madrid, núm. 139, lunes 22 de agosto de 1814 , p. 1125. 
sus sesiones supondría faltar a sus "obligaciones más sagradas", malgastar "en el salón de Cortes cuatro horas que pudieran y debieran emplear más útilmente". Las leyes no podian fomentar distracciones en materias que no eran de la competencia femenina. Ni asistencia a las cortes, ni leer periódicos... "las casas se perderán si no se prohibe su lectura [periódicos] a las que no nacimos sino para coser, hilar y gobernar la casa". 54

$\mathrm{Ni}$ en la Constitución ni en cuantos decretos emanaban de ella parecía encontrarse nada que mejorase la vida de las mujeres "condenadas a hablar de sus labores y sin más adelantos que los que por si vayan haciendo a hurtadillas de sus ocupaciones caseras..." Al poco de iniciarse el trienio liberal se entendió que ni la enseñanza de la Constitución iba con ellas.

¿se han de ver privadas las que están en ellos [en las escuelas] de que se las enseñen sus obligaciones civiles, y de que se las explique la constitución política de la monarquía española? ¿No tienen acaso las mugeres otro lazo que las una a la nación, que el del reconocimiento al hombre y la casualidad que las ha hecho nacer en ella? ¡Pobres mugeres! según veo ni aun los artículos 366 y 368 se han hecho para vosotras. Se conoce muy bien que los hombres han sido los legisladores, y que siendo liberales por principios, son con nuestro sexo tiranos por costumbre. Que no se quejen del trabajo que les pueda costar el despreocupar a sus hijos de las primeras impresiones que les imbuyan las mugeres en su infancia; que no descuiden tanto un punto que tiene en la sociedad mas influencia de lo que parece, y que tomen las medidas y consideraciones que ni tu ni yo sabremos proponer."55

De hecho, en los anuncios sobre el establecimiento de nuevas casas de educación para niñas se prometian muchas enseñanzas aparte de leer, escribir, contar y doctrina religiosa, pero la explicación de la Constitución se impartiría "solo para las que lo quieran sus padres." 56 Las pocas nociones que podian tener vendrían de la obligada explicación que de la constitución debía hacer el cura en misa o de las sociedades patrióticas que pronto serían cuestionadas. Pocos diarios se ocuparán, en vista del plan de enseñanza que se iba a discutir en las Cortes, de la mujer, cuyo estado de ignorancia se debía a una instrucción basada en pasar el tiempo "cosiendo o bordando". 57

En el proyecto de decreto sobre el plan general de enseñanza presentado a las Cortes en 1820 para su discusión, la enseñanza de las mujeres quedaba reducida al título XI, de los XIII que contenía. Ninguno de los títulos anteriores que regulaban la primera, segunda y tercera enseñanza y las instituciones responsables de la instrucción pública, parecian tener que ver con las niñas, ni

54 “Debe permitirse que asistan las mugeres a las galerias de las Cortes?”, El Censor, n. 34, sábado 24 de marzo de 1821, pp. 267-298, cita en p. 272.

55 Suplemento a la Miscelánea de comercio, artes y literatura, jueves 6 de abril de 1820, p. 4.

56 Diario de Madrid, 2 de octubre de 1820, p. 468.

57 El Conservador, núm. 170, martes 12 de septiembre de 1820. En el mismo sentido se expresaba El Diario constitucional de Barcelona: "seria ocioso detenernos en ponderar el mal estado en que se hallan nuestras escuelas de niñas. Muchas hay y tal vez serán las más en que la calceta es la única labor que se las enseña. Donde aprenden el bordado ya es un colegio para ellas y si se añade la costura ya ha llegado al colmo de la perfección. En cuanto a leer, escribir, contar, preceptos de moral no se hable”, Diario constitucional de Barcelona, núm. 179, 28 de junio de 1821. 
siquiera lo dispuesto para las escuelas de primeras letras. De hecho cuando se hacía referencia al maestro se decía que lo era de primeras letras y por contra, de la maestra se decía siempre de costura. Hay que observar también que cuando se debate sobre si implantar la enseñanza primaria antes de terminado el plan general, como hemos visto, la enseñanza de la mujer no había sido aún discutida y sin embargo se entendió que la primera enseñanza ya estaba aprobada.

Las escuelas de primeras letras, que la Constitución establecía hubiera en todos los pueblos, estaban dirigidas solamente para enseñar a los niños, no a las niñas. A ellas, de forma separada y marginal, se refería el proyecto de 1820 en dos artículos: "Se establecerán escuelas públicas, en que se enseñe a las niñas a leer, escribir y contar, y a las adultas las labores y habilidades propias de su sexo" (art. 124) y "El Gobierno encargará a las Diputaciones provinciales que propongan el número de estas escuelas, los parajes en que deban situarse, como tambien su dotacion y arreglo" (art.125).

No hubo ninguna modificación con respecto al proyecto de 1814, cuyos artículos, con distinto número, se presentaron con el mismo dictado. Llama la atención no obstante que en el debate de estos artículos quedara suspendida la votación del artículo 124 "por haber manifestado algunos diputados que no se expresaba en él la verdadera enseñanza que debian tener las niñas". Nada más recogen los Diarios de sesiones, tan solo que una vez reformado la comisión de instrucción pública lo presentó con otros términos: "se establecerán escuelas públicas en que se enseñen a las niñas las labores propias de su sexo y lo que previene en el art. 8 respecto de los niños. ${ }^{58}$ Dicho art. 8 hacía referencia a los contenidos de su educación primaria, donde se incluía además de leer, escribir y contar, el estudio del catecismo constitucional. Sin embargo, extrañamente, a pesar de aprobarse la enmienda, el reglamente aprobado en 1821 vuelve a formular dicho artículo en los mismos términos en que lo hacía el proyecto de 1820. Volvía a quedar excluida la mujer del estudio de la Constitución. No le estaba prohibida pero tampoco parecía obligatoria su enseñanza.

En cuanto al número de escuelas no se establecía que en todos los pueblos hubiera una escuela para las niñas sino que dejaba a la Diputación proponer las que estimara convenientes en la provincia.

El Reglamento interino de 1822 no hizo sino confundir más los contenidos de su enseñanza al establecer en el art. 66 que en las escuelas de niñas se "seguirá en un todo el mismo plan, sistema y orden que en las de niños en la parte de instrucción literaria". ¿A qué se refería con la instrucción literaria? También el Censor se lo preguntó sin llegar a entender su sentido. El artículo siguiente nada clarificaba: "Por las mañanas se enseñará a todas la parte literaria y por la tarde las grandecitas se dedicarán a las labores propias del sexo y las demás seguirán su instrucción en la parte literaria; pero sin perjuicio de que en esta parte se haga alguna variación o modificación cuando lo exijan las circunstancias del pueblo o local" (art. 67).

58 Diario de sesiones, 12 de junio de 1821, pp. 2212-2213. El mismo texto se recoge en la prensa, véase, Miscelánea de comercio, politica y literatura, núm. 472, jueves 14 de junio de 1821 , p. 3 o El Universal, núm. 165, jueves 14 de junio de 1821, p 3. 
De su vigilancia se encargarian un cierto número de señoras, "de aquellas que tengan más celo por el bien público e instrucción, nombradas por los ayuntamientos" (art. 68).

\section{MAESTROS Y MAESTRAS}

\subsection{Maestros de primeras letras}

Uno de los graves problemas de las escuelas eran los sujetos encargados de impartir las enseñanzas, no solamente por su falta de preparación -alguno incluso era analfabeto59- sino también porque en muchos casos los maestros eran clérigos y frailes que fomentaban la superstición para mantener su poder espiritual rechazando el uso de la razón. Se decía que "la cesión casi absoluta que se habia hecho de la enseñanza a la potestad espiritual es la culpable de la escasez de talentos; abortó el tribunal de la inquisición y privó de la libertad de pensar y de toda comunicación con las naciones más ilustradas".60 Por otra parte, la mayoría de los maestros tenía varias ocupaciones para poder subsistir: además de maestros eran sacristanes, secretarios de ayuntamiento, fiel de fechos, organistas...61 En algún caso incluso era pastor o tenía que dedicarse a la labranza y otras tareas gran parte del año "cerrando sus aulas todo este tiempo como ocurre en Palencia, León, Asturias... en que solo 5 ó seis meses están abiertas al año".62 Era necesario poner al frente de las escuelas maestros preparados pero no lo conseguirian si los ayuntamientos no ofrecían una renta anual que les permitiera vivir con dignidad.

Respecto de su preparación, aunque no había todavía una escuela para formarlos, se volvó a exigir que los maestros que el Estado pagaba deberían necesariamente ser examinados, en la capital de la respectiva provincia "o donde y por quienes las diputaciones de provincia determinen" para obtener el título. ${ }^{63}$ Tomando como ejemplo a Valencia, veamos cómo se concretan en la práctica las disposiciones que se fueron aprobando al respecto.

El examen, que debía ser público, versaba sobre las materias que el niño tenía que aprender esto es, lectura, escritura, aritmética y el catecismo que comprendia los dogmas de la religión, máximas de buena moral y los derechos y obligaciones civiles (art. 12 del reglamento de instruccion publica 1821). El reglamento interino de 1822 especificaba además que los examinadores le harían

59 El ayuntamiento de San Fulgencio comunicaba a la diputación de Valencia en 1820, II, p. 37) que componiéndose de 195 vecinos carecía de toda instrucción porque el maestro "tiene solos 180 libras y no sabe leer ni escribir".

60 Diario de Madrid, núm. 68, 9 de marzo de 1813. En la Gazeta de 25 de marzo de 1812 el mismo escritor ponía de relieve que los culpables de los males de España no eran los franceses. Otro artículo en el mismo sentido puede verse en Semanario patriótico, núm. 97, jueves 13 de febrero de 1812 .

61 José Alcácer de Tirig era fiel de fechos; Manuel Monte de Argelita, secretario de ayutamiento; José Pizarro de Chiva, organista, Libro de registro de entradas y salidas de expedientes, vol 1 , 1820 , pp. 20, 35 y 63, archivo de la diputación de Valencia.

62 Memoria leida a las Cortes por el encargado del Despacho de la secretaría de gobernación de la península, apéndice segundo al núm. 7, 4 de marzo de 1821, pp. 85-105.

63 Reglamento general de instrucción pública decretado por las Cortes en 29 de junio de 1821 , Madrid, 1821. 
preguntas para que no les quedase ninguna duda de que el candidato sabe comunicar a los niños esos contenidos (art. 3).

Era el candidato a maestro quien tenía que solicitar se le señalase el día y hora de examen, aportando previamente los documentos que acreditaran su instrucción y su "arreglada conducta y moralidad". 64 Tras la solicitud, la diputación fijaba la fecha para solo unos días después, en la mayoría de las ocasiones el sábado siguiente. ${ }^{65} \mathrm{En}$ las actas de la diputación se van recogiendo estas solicitudes, así como el resultado del examen. En Valencia solo consta un reprobado: Cristóval Molinos, vecino de la villa de Forcall que se mandó comunicar al ayuntamiento de la villa. 66

El primer maestro en solicitar examen sería José Avella, vecino de Lucena (Castellón) y ese mismo día se aprueba la comisión encargada de examinar a los maestros. El 10 de mayo de 1820 se acordó "que el examen de este interesado y cualesquiera otros que se ofrezcan en lo succesivo se tengan a presencia del sr. vocal D. Mariano Tortosa y de los demás señores diputados que gusten asistir; debiendo concurrir en calidad de examinadores el Dr. D. Pedro Cano presbítero beneficiado de la parroquial iglesia de San Bartolomé de esta ciudad, un padre esculapio aquel que elija el Rdo. Padre Rector de las Escuelas pias ${ }^{67}$ y D. Francisco Pantaleón Rico maestro de primeras letras ${ }^{68}$ y que los exámenes se tengan en el salón de sesiones avisando un día antes por medio del correspondiente oficio a los referidos examinadores para que concurran a la hora que se les señale, en el concepto de que deberá extenderse formal acta de la aprobación o desaprobación del examinando en libro separado de los acuerdos de la Diputación provincial". ${ }^{69}$ El segundo, Cristóbal Nadal y Lisardo de Alcira solicitaría fecha de examen el 12 de junio de 1820 y el 14 sería examinado.70

64 "Se dio cuenta de un expediente de D. Cristobal Nadal y Lisardo vecino de la villa de Alcira solicitando se le señale día y hora para el examen de maestro de primeras letras y habiéndose encontrado competentemente instruido por la sumaria que acompañó de limpieza de sangre y arreglada conducta y moralidad del interesado, se acordó proceder al examen que solicita el día 14 del corriente por los señores examinadores nombrados en sesión de 10 de mayo último y constando de la ideoneidad por certificación que deberá estender el presente secretario se de cuenta para la aprobación con arreglo al art. 12 del cap. $2^{a}$ del soberano decreto de las Cortes generales y extraordinarias de 26 de junio de 1813", Actas de la diputación de 12 de junio de 1820, Archivo de la diputación de Valencia.

65 El Proyecto de reglamento recogía que debían convocar el examen dentro de los 8 días de la presentación de la solicitud, art. 8. He podido constatar que, al menos en el caso de Valencia se cumplia nada más comenzar el trienio, antes de aprobarse el plan y por supuesto de poner en marcha en proyecto de 1822 .

66 Actas de la diputación 4 de febrero de 1822, p. 64, Archivo de la diputación de Valencia.

67 Designaría al padre Mariano de los Dolores.

68 El 27 de enero de 1822 el secretario dio cuenta del fallecimiento de D. Francisco Pantaleón Rico, uno de los examinadores y se acordó mientras recaía nuevo nombramiento concurriera en su lugar otro de los Padres del Colegio de la Escuela Pía, actas de la diputación de Valencia, 27 de enero de 1822, p. 61, Archivo de la diputación de Valencia.

6910 de mayo de 1820, p. 104 r y v. presidió su examen Mariano Tortosa. Como nuevos examinadores de maestros de primeras letras se nombraron a los presbiteros Miguel Moncho y José Soliveres y a Manuel Batanero, 29 de julio de 1822, p. 140.

7010 de mayo de 1820, p. 104 r y v., presidió su examen Mariano Tortosa; Cristóbal Nadal pide examen el 12 de junio de 1820 y se realiza el 14. Presidiò Gerónimo Osca. 
Ningún maestro más solicita que se le examine hasta después de aprobado el Reglamento general de instrucción pública en junio de 1821. Quizás debió influir la decisión de la diputación de expedir los títulos de manera provisional hasta la aprobación de dicho reglamento. ${ }^{71}$

Los exámenes se celebrarán siempre en el salón de sesiones de la diputación a las cuatro de la tarde. Excepcionalmente, cuando las circunstancias impedian al maestro acudir a Valencia, sería el ayuntamiento el encargado de examinarlo. Tal fue el caso de José Vergel de la Maza, quien solicitó se le admitiera a examen dando comisión al ayuntamiento de Orihuela por "no permitirle sus achaques presentarse" en Valencia. La diputación, a través del jefe político pidió informes al ayuntamiento sobre lo expuesto en la instancia de Vergel, así como sobre "su moralidad, instrucción y aptitud de este interesado para el desempeño del magisterio, expresando si es afecto al sistema constitucional". ${ }^{72}$ El título en cualquier caso lo expedia la diputación:

Resultando del expediente a instancia de D. José Manuel Vergel de Maza, vecino de la ciudad de Orihuela, el examen para Maestro de primeras letras sufrido ante aquel ayuntamiento, encontrándole los examinadores suficientemente instruido en leer, escribir, contar, doctrina cristiana, constitución de la Monarquía, ortografía y aritmética, según las muestras que se acompañaban; se mandó expedir el correspondiente título haciendo mérito de aquella circunstancia por indisposición física del interesado. ${ }^{73}$

Aprobado el Reglamento general de instrucción pública de 1821 fueron pocos los maestros que decidieron obtener su titulo hasta la puesta en marcha del reglamento interino de 1822. Concretamente realizaron el examen José Martínez de Tavernes de Valldigna ${ }^{74}$, José Manuel Vergel de Maza, vecino de la ciudad de Orihuela ${ }^{75}$, Juan Bautista Cerdá, ${ }^{76}$ José Pascual Gómez, ${ }^{77}$ Joaquín

71 "El 16 de junio de 1820 el secretario leyó la certificación librada por el mismo con referencia al libro de exámenes para maestros de primera educación y estendida en el expediente promovido por Cristóbal Nadal y Lisardo de la que resulta que examinado este a presencia del señor don Gerónimo Osca en el día 14 del corriente por don Pedro Cano, presbitero, el padre Mariano de los Dolores religioso esculapio y Don Francisco Pantaleón Rico, se le encontró por dichos examinadores apto, idoneo y en disposición de poder obtener la aprobación para maestro de leer, escribir y contar y habiendo a más informado a la vez dicho S. Osca no solo sobre la aptitud de dicho Nadal si que también sobre lo que propusieron los referidos examinadores en orden a que para fomentar la aplicación y el estudio de los maestros convendría se expidieran títulos temporales con la obligación de presentarse nuevamente a examenes concluido el término que se les señalase; se acordó la aprobación del referido Cristobal Nadal y Lisardo y que se le expida el correspondiente título para ejercer el magisterio por ahora y hasta que las Cortes establezcan el plan general de estudios, para cuyo caso quedará sujeto a lo que se establezca en dicho plan", Actas de la diputación de Valencia, 16 de junio de 1820, sin foliar, Archivo de la diputación de Valencia.

72 Libro de registro de entradas y salidas de expedientes vol. 3, 1 de marzo de 1821, p. 257, Archivo de la diputación de Valencia.

73 Archivo de la diputación de Valencia, Actas, 15 de octubre de 1821.

74 Ibid., 31 de octubre de 1821.

75 Ibíd., 15 de octubre de 1821.

76 Ibíd., 3 de enero de 1822, 50-51.

77 Ibíd., 3 de enero de 1822, 50-51. 
Gallete de Montanejos, ${ }^{78}$ Joaquín Julián de Castielfabib, ${ }^{79}$ José Mir de Valencia ${ }^{80}$ Tomás Ortí,81 Manuel Conesa, vecino de Morella,82 Manuel Tomás, vecino de Nules, ${ }^{83}$ Vicente Gil, presbítero, ${ }^{84}$ Ramón Campell, ${ }^{85}$ Vicente Faus y Farga de Benaguacil, 86 Salvador Ferreres de Chiva. ${ }^{87}$

La entrada en vigor del reglamento interino supuso algunas modificaciones con respecto a los exámenes, conformación de los tribunales y expedición de títulos. Por una parte, junto a justificación legal de buena vida y costumbres habia que demostrar su adhesión a la Constitución. ${ }^{88} \mathrm{El}$ Censor opinaba que probar esa adhesión legalmente era "querer que el número de pretendientes sea escaso o que muchos de ellos presenten justificaciones falsas". Es lógico que se requiera de los maestros que no hablen mal de la Constitución, que no la impugnen o desacrediten. Pero exigir ser adictos ¿cómo se justifica? "Todo el que quiera ser maestro de primeras letras dirá que es tan adicto a la Constitución como el mismo Riego y lo probará legalmente del modo con que pueden o suelen probarse estas cosas; pero cuántos de ellos serán en su interior tan serviles como los siervos del serrallo?"89

Era causa de separación además el dar "alguna prueba positiva de hecho de no ser adicto al sistema constitucional" art. 24. Por este motivo se abrieron muchos expedientes que debía resolver una diputación, desbordada por otros asuntos. Por ejemplo, tras informar el jefe político a la diputación de que en las escuelas del Convento de Dominicos de Valencia la instrucción de los niños respecto de las obligaciones civiles era muy deficiente, "lo cual era un medio indirecto de eludir el artículo 366 de la Constitución y el 12 del reglamento de instrucción pública," la diputación resolvió que el ayuntamiento nombrase interinamente tres maestros para estas escuelas, dándole cuenta de las personas que eligiese. Los pueblos también se quejan. El ayuntamiento de Alacuás abrió un expediente al maestro por varias faltas cometidas en el desempeño del cargo y tramitó a la diputación su remoción. La tramitación de estos expedientes era

78 Ibid., 15 de diciembre de 1821.

79 Ibid., 15 de diciembre de 1821.

80 Ibíd., 15 de diciembre de 1821.

81 Ibíd., 3 de enero de 1822, 50-51.

82 Ibíd., 3 de enero de 1822, 50-51.

83 Ibid., 3 de enero de 1822, 50-51.

84 Ibíd., 25 de abril de 1822, p. 108.

85 Ibíd., 25 de abril de 1822, p. 108.

86 Ibíd., 11 de junio de 1822 .

87 Ibíd., 15 de julio de 1822, p. 131.

88 Art. 1. Las personas que aspiren a ser profesores de primera educación han de reunir las circunstancias de tener buena vida y costumbres, adhesión a la constitución política de la monarquía y la competente instrucción en los diferentes ramos que han de enseñar y en el método de comunicar a los niños estos conocimientos. También art. 8.

89 Explicación sobre el estado de la enseñanza pública, hecha a las Cortes por la dirección general de estudios, El censor, 1 de junio de 1822, pp. 473-474. Al tomar posesión de su destino debían prestar juramento a la Constitución. (art. 21). 
lenta, pesada y a veces ni siquiera se concluía. ${ }^{90}$

Hasta la puesta en práctica del reglamento interino de 1822 , los títulos los expedía la diputación y solo había una clase de maestro. A partir de 1822 los expediria la dirección general de estudios, previa certificación de la diputación y no serian gratuitos. Los títulos podian ser de tres clases:

- Maestro local: habilitaba para poder enseñar en pueblos de la provincia donde hubieran realizado el examen, con menos de 300 vecinos. Se realizaba en la capital de esa provincia por una comisión presidida por un diputado provincial e integrada por tres maestros públicos de primeras letras sacados a sorteo la víspera del examen entre todos los que hubiese en la provincia. El examen duraría una hora.

- Maestro provincial: los habilitaba para enseñar en todos los pueblos de la provincia, incluida la capital. El examen se realizará en la capital por una comisión integrada por un diputado provincial -presidente-, un catedrático de matemáticas de la universidad elegido por la diputación y dos maestros. El examen duraria una hora y media.

- Maestro general, pueden enseñar en cualquier pueblo de la monarquía. El examen se hacia en Madrid, en la dirección general de estudios y duraba dos horas.

Los maestros aprobados con anterioridad por la diputación pasaban a considerarse provinciales. Y los titulados tenian preferencia frente a los no titulados a la hora de elegir vacante. Esto también derivó en expedientes en los que los maestros reclamaban una plaza ocupada por otros sin título.

En cumplimiento de los artículos 6 y 7 se nombró como examinador a Ramón Teruel, catedrático de matemáticas de la universidad de Valencia y se acordó que el sorteo de los maestros examinadores se hiciese por el presidente de la comisión de exámenes con el secretario. ${ }^{91}$ Siendo la diputación responsable por varios decretos y órdenes del gobierno de los adelantos y progresos en la instrucción de la juventud, resolvió dirigir a los ayuntamientos una circular para que se presentaran a exámenes los maestros de primeras letras que tuvieren escuelas dotadas de los fondos públicos y carecieran de títulos, debiendo remitir testimonio de los que lo hubieren obtenido con expresión del tiempo y autoridad por quien se expidió. 92

Desde este momento la mayoría de títulos que se solicitan son de maestro provincial de primeras letras porque permitía al maestro ocupar las plazas mejor dotadas. Vicente Gascón de Caudiel, maestro provincial, ${ }^{93}$ José Alayrac Rueda,

90 Archivo de la diputación de Valencia, Libro de registro de entradas y salidas de los expedientes, 1823, vol. 6, p. 59 v. El ayuntamiento abre el expediente el 14 de noviembre de 1822 , p. $59 \mathrm{v}$, el 14 de febrero de 1823 presenta sus alegaciones el maestro, Francisco Ballester. La diputación pide el 27 de febrero al ayuntamiento que, a la vista del escrito presentado por el maestro alegue lo que considere. Pero no hay más actuaciones reflejadas en el libro de registro de la diputación.

91 Archivo de la diputación de Valencia, Actas, 29 de octubre de 1822, p. 45.

92 Ibíd., 5 de diciembre de 1822, p. 71.

93 Ibíd., 31 de octubre de 1822, p. 48v y r y 7 de noviembre de 1822, p. 57. 
vecino de Geldo, maestro local, 94 José Delfin de Murviedro, maestro provincial,95 José Bañuls vecino de Carlet, maestro provincial, ${ }^{96}$ Lorenzo Calpena presbítero de Buñol maestro local de primeras letras, ${ }^{97}$ Antonio Paralaygua maestro provincial, 98 Bernardo Sapiña presbitero de Cullera, maestro provincial,99 Joaquín Llaudes, vecino de la Alcudia de Carlet maestro provincial, ${ }^{100}$ Salvador Ferreres de la de Chiva maestro local de primeras letras, ${ }^{101}$ Joaquín Laudes maestro provincial,102 Salvador Ferreres maestro local,103 José Roig vecino Valencia, maestro local, ${ }^{104}$ Antonio Errades vecino de esta ciudad para maestro provincial,105 Juan Amorós de Faura, provincial,106 Joaquín Tomás de Alcira, provincial. 107

Las vacantes podian ser debidas a escuelas de nueva creación o por fallecimiento o jubilación del maestro. El ayuntamiento estaba obligado a poner edictos en todos los pueblos cabeza de partido de su provincia y publicar en los periódicos de la provincia -e incluso de la capital de la monarquia- las plazas de maestros vacantes para que los aspirantes pudieran optar (art. 14). Se definian todas las características de la misma. Por los anuncios podemos advertir las diferencias de dotaciones y de dónde procedían las rentas. En la villa de Villacastín en Segovia ofrecian pagar 3.000 reales anuales además de cuatro obradas de tierra ${ }^{108}$; en la Aldea del Rey, la dotación del maestro era de 200 ducados, treinta fanegas de trigo por año y casa pagada, todo a costa de los bienes propios menos 15 fanegas de trigo que pagaban los padres que podian y por los que no, lo satisfacía el cura párroco. ${ }^{109}$ En la villa de Fuente el Saz de Jarana se pagaban 10 reales diarios pagados de los propios y de los niños. ${ }^{110}$ En la villa de Arévalo de la provincia de Ávila al maestro se le pagaban 12 reales diarios, a la maestra 9 reales. ${ }^{111}$ En Villanueva del Pardillo de Madrid, 5 reales

\footnotetext{
94 Ibid., 16 de noviembre de 1822, p. 63 v.

95 Ibid., 2 de diciembre de 1822, p. 69.

96 Ibid., 16 de diciembre, p. 79 y 19 de diciembre de 1822, p. 80 v.

97 Ibíd., 9 de enero de 1823, p. 4 y 13 de enero de 1823, p. 6.

98 Ibíd., 13 de enero de 1823, p. 6 v, 6v y 7r. No pudo presentarse en la fecha acordada y volvió
} a solicitarlo 22 de febrero, 40v y aprueba el 28 de febrero de 1823, p. $41 \mathrm{v}$.

99 Ibíd., 27 de enero de 1823, p. 16 y 3 de febrero de 1823, p. 21 r y v.

100 Ibíd., 27 de enero de 1823, p. 16.

101 Ibidem.

102 Ibid., 30 de enero de 1823, p. 18 v.

103 Ibidem.

104 Ibid., 3 de febrero de 1823, p. 22 y 6 de febrero de 1823, p. 24.

105 Ibíd., 11 de febrero de 1823, p. 26 v.

106 Ibíd., 19 de febrero de 1823, p. 36 v y 22 de febrero, p. 40 v.

107 Ibidem.

108 Diario de Madrid, sábado 27 de enero de 1821. También y con más datos en Miscelanea de comercio, 27 de enero de 1821.

109 El Universal 9 dfe febrero 1821.

110 Diario de Madrid, 10 de febrero de 1821.

111 El Universal, jueves 15 de febrero de 1821 . 
diarios y casa habitación de los propios y un cuarto que le dan los niños los sábados. ${ }^{112}$ En la villa de Salmerón en la Alcarria provincia de Guadalajara, de los tres mil reales que se pagan al maestro, dos mil eran de los propios y los restantes de unas memorias pias. ${ }^{113}$ En la villa de Leganiel en Cuenca los 2.000 reales del maestro eran pagados por el ayuntamiento y por los niños, los de la clase de escritura abonaban dos reales mensuales, dos cuartos los sábados, y seis celemines de trigo por año de iguala y la clase de leer pagaban un real mensual, un cuarto los sábados, y tres celemines de trigo al año. También se le daba casa libre de todas contribuciones. Este pueblo tenía 260 vecinos. ${ }^{114}$

De su elección, vigilancia de su conducta y remoción entendían las autoridades locales a las que la Constitución había dejado el cuidado de aquellas escuelas. ${ }^{115}$

\subsection{Las maestras de niñas o de costura}

Durante los años de Cádiz, si los informes respecto al estado de la enseñanza de los niños eran decepcionantes, los relativos a las niñas no podian ser más demoledores. En 1808 el intendente de Valencia informaba que, "dirigidas sin tino por maestras que carecen de toda instrucción", la mayoría de estas escuelas eran inútiles o incluso perjudiciales. En ellas reinaba el desorden y las niñas salian sin saber leer ni escribir. Proponía que la casa de enseñanza de Valencia, fundada por el obispo Mayoral, se convirtiera en escuela para formar maestras. ${ }^{116}$ En 1813 el diputado Marcial López presentaba en las Cortes un Sistema de educación pública general conforme al espíritu de la constitución politica de la monarquía española. Al referirse al estado de la educación de las niñas se lamentaba de que solo ofrecía motivos para llorar la frivolidad o la ignorancia en que habian sido educadas: "no se ve en los pueblos sino tropas de muchachas desaliñadas, reunidas únicamente para hacer el mal, sin recato ni civilidad, aprendiendo y enseñando palabras obscenas..." Juzgaba que las niñas debian recibir "de sus maestras las instrucciones peculiares a las mugeres", pero que "del leer, escribir y contar" se encargaran maestros hasta nueva providencia. Dejaba así patente que las pocas maestras que había lo eran solo de costura sin tener preparación suficiente para enseñar a leer o escribir a las niñas, a pesar de la real cédula de $1783 .{ }^{117}$

Los conocimientos exigidos a las maestras dependian obviamente de las enseñanzas que debían impartir y al igual que los maestros estaban obligadas a poseer un título que acreditara su formación, aunque la mayoría no lo poseía. En

112 Diario de Madrid, 16 de febrero de 1821.

113 Nuevo diario de Madrid, 4 de julio de 1821.

114 Nuevo diario de Madrid, 14 de enero de 1822.

115 El proyecto de Decreto sobre el arreglo general de la enseñanza pública de 1814 y el de 1820 el mismo dictado en arts. 11,12 y 13.

116 Expediente sobre la proposición hecha por Francisco Javier Aspiroz, intendente del reino de Valencia sobre la instrucción y mejora del método de educación y enseñanza en las escuelas de primeras letras, Archivo histórico nacional, sección Consejos, legajo 12004, exp. 56.

117 Presentada a las Cortes el 12 de noviembre de 1813 por PDMAL (Marcial Antonio López, p. 235, núm. 47), Madrid, imprenta de Núñez, 1820, pp. 57-58, p. 59. 
1771 ya se prescribía. Las maestras de niñas, para permitírseles la enseñanza, debían, precediendo el informe de vida y costumbres, examinarse de la doctrina cristiana "por persona que dipute el Ordinario y licencia de la Justicia, oído el Síndico y Personero sobre las diligencias previas." Además, debían ser examinadas delante de otras maestras de costura, bordado y también lectura. ${ }^{118}$ Conforme a dicha disposición, en 1808 Mariana López se examinó de maestra en Madrid. Las diligencias practicadas, previa presentación de los documentos exigidos y solicitud al Consejo de Castilla para ser examinada, ${ }^{119}$ fueron las siguientes:

Ante el señor alcalde D. Antonio Cano Manuel, en su posada, comparecieron las maestras de niñas, que tienen aceptado el nombramiento de examinadoras, Dña. Manuela Braseras y Dña. María Theresa Berjano, a las que dicho señor por ante mi el escribano ratificó en su juramento y bajo él prometieron hacer bien y fielmente su encargo. $\mathrm{Y}$ habiendo concurrido Dña. Mariana López a virtud del requerimiento que la hice, la examinaron aquellas haciéndola coser a la española, inglesa y francesa, vordar al pasado, al vastidor y tambor, hacer letras y flores en dechado y otras obras propias de la escuela. Y concluido, separada la Dña. Mariana López, dixeron: hallan a esta capaz e inteligente para el desempeño de Maestra de niñas, con habilidad suficiente para ello. Y enseguida se la hizo leer en un libro y lo executó corriente. Por todo lo qual dichas Maestras la aprobaron. ${ }^{120}$

Ya hemos visto los trámites que el maestro debía seguir para obtener su título. Sin embargo, en 1821 no estaba claro quién debía encargarse de examinar a las maestras. Cuando María Antonia Más solicita a la diputación provincial de Valencia ser examinada de maestra, como lo hacían los maestros, la diputación acudió a la real sociedad económica de amigos del país de Valencia para informarse sobre qué reglas debía seguir. La contestación de la sociedad indicaba que respecto de la mujer poco había cambiado.

Esta comisión en vista del oficio de 10 del pasado mes ha tomado quantos informes y noticias ha podido para poder responder al preguntado que usted le hace. La práctica que en esta materia se ha seguido ha sido presentar, la que solicitaba tal aprovación, un memorial al corregidor acompañado del abono del alcalde del barrio y certificación del cura de la parroquia. En el día señalado se presentaba en casa del corregidor a ser examinada para lo que havía convocada al intento una maestra para el examen de las labores del

118 "Requisitos para el ejercicio del magisterio de Primeras letras", Real provisión del Consejo de 11 de julio de 1771, Novísima Recopilación, libro VIII, tít. 1, ley 2. "Establecimiento de escuelas gratuitas en Madrid para la educación de niñas; y su extensión a los demás pueblos", Real cédula de 11 de mayo de 1783, Novisima Recopilación, Libro VIII, tít. 1, ley 10.

119 Partida de bautismo, certificación del cura párroco de haberla examinado en la doctrina cristiana así como informe de la diputación de caridad del barrio de Leganitos de que es "de buena crianza, vida y conducta arreglada, de buenas calidades, moderación, aplicación, capacidad e instrucción, por cuyas circunstancias, su recogimiento y cristianos procederes...”

120 Expediente relativo a la solicitud hecha por Mariana López para que le sea expedida certificación del examen que realizó y aprobó como maestra de niñas ante el extinguido Consejo de Castilla, 1810, Archivo Histórico Nacional, Consejos, 50068, exp.19. 
sexo y un maestro para el examen de leer y doctrina cristiana, verificado el examen se le expedía el título por dicho magistrado."121

Nada se le exigía respecto del conocimiento de la Constitución porque no estaba previsto que la enseñara. Además, así como se deja constancia en las actas de la diputación de aquellos maestros que solicitaron examinarse, no hay mención alguna de las maestras. Sí se reflejan sus solicitudes de examen o sus quejas en los libros de registro de entradas y salidas de expedientes.

Su consideración con respecto a los maestros era inferior y ello también se reflejaba en el sueldo. A modo de ejemplo podemos ver las diferencias, en las escalas de graduación que, para dotar los maestros de la enseñanza primaria de ambos sexos, siguiendo las bases del vecindario y el decreto de Cortes de 29 de junio de 1822, presentó la comisión de contribución a la Diputación provincial de Valencia.

Escala para los maestros de enseñanza primaria

$\begin{array}{lcc}\text { Vecindario } & \text { Dotación del minimum } & \text { id del maximum } \\ \text { Hasta } 100 & 800 \mathrm{r} & 1000 \mathrm{r} \\ \text { De } 100 \text { a } 150 & 1.200 \mathrm{r} & 1500 \mathrm{r} \\ \text { De } 150 \text { a } 200 & 1.500 \mathrm{r} & 2000 \mathrm{r} \\ \text { De } 200 \text { a } 300 & 2.000 \mathrm{r} & 2.500 \mathrm{r} \\ \text { De } 300 \text { a } 400 & 2.500 \mathrm{r} & 3.000 \mathrm{r} \\ \text { De } 400 \text { a } 500 & 3.000 \mathrm{r} & 3.500 \mathrm{r}\end{array}$

De 500 a 1.000, cien reales de aumento por cada cincuenta vecinos, de suerte que el pueblo que se forme de quinientos veinte vecinos, su dotación será de tres mil quinientos cuarenta reales. El de quinientos cuarenta vecinos, de tres mil quinientos ochenta reales y asi succesivamente, mas estas asignaciones lo serán para las escuelas puramente de primeras letras, pues en las que se enseñen los demás conocimientos que expresa el párrafo 13, art. 9, tit. 2 del citado decreto, deben ser cuando menos de quatro mil quinientos reales de vellón.

Id para las maestras de Costura

$\begin{array}{lcc}\text { Vecindario } & \text { Dotación del minimum } & \text { id del maximum } \\ \text { Hasta } 100 & 450 \mathrm{r} & 600 \mathrm{r} \\ \text { De } 100 \text { a } 150 & 600 \mathrm{r} & 800 \mathrm{r} \\ \text { De } 150 \text { a } 200 & 800 \mathrm{r} & 1.000 \mathrm{r} \\ \text { De } 200 \text { a } 300 & 1.000 \mathrm{r} & 1.200 \mathrm{r} \\ \text { De } 300 \text { a } 400 & 1.200 \mathrm{r} & 1.500 \mathrm{r} \\ \text { De } 400 \text { a } 500 & 1.500 \mathrm{r} & 1.800 \mathrm{r} \\ \text { De } 500 \text { a } 700 & 1.800 \mathrm{r} & 2.000 \mathrm{r} \\ \text { De } 700 \text { a } 1.000 & 2.000 \mathrm{r} & 2.500 \mathrm{r}\end{array}$

121 Archivo de la Real Sociedad económica de amigos del País de Valencia, 3 de enero de 1821, Caja 68, legajo IV. Educación, n. 7, año 1821. 
En los pueblos que lleguen a 1.000 vecinos se establecerán dos de estas enseñanzas con la dotación cada una que según el minimum y el maximum detallado para los de quinientos a setecientos vecinos, juzguen los ayuntamientos, habida consideración al número de niñas que asistan a la costura, observándose lo mismo en los pueblos cuyo vecindario sea de mil quinientos a dos mil vecinos y así succesivamente, en el concepto de que por cada quinientos vecinos, debe establecerse una enseñanza de niñas. ${ }^{122}$

\section{BUSCANDO DOTACIÓN}

Para organizar las escuelas de primeras letras era necesario saber si en los pueblos había o no establecimientos de enseñanza, si faltaban o eran excesivos, si los anteriores se debían conservar, sus progresos o atrasos, los recursos con que contaban... Iniciado el Trienio, la circular de 29 de mayo de 1820 ordenaba a los jefes politicos con ayuda de la diputación y los ayuntamientos recopilar este tipo de información. Debian formar un catálogo de las escuelas expresando el nombre del establecimiento, el objeto de su fundación, sus patronos, sus rentas y procedencia de las mismas, estado en que se hallaba el establecimiento, mejoras o retrocesos que hubiera tenido y mejoras de las que era susceptible. Pero fue un fracaso. Unos porque entregaron unos resúmenes que no resultaron muy útiles; otros porque no llegaron a enviarlos por la dificultad que entrañaba reunir esos datos. Como exponía el ministro no quiso insistir "para no hacer odioso el sistema constitucional..., esperando que el tiempo disipara sus temores". ${ }^{123}$ Ya se habia intentado antes, el intendente de Valencia en 1808 expuso en su informe cómo para la formación de estos estados, los pueblos presentaron mucha resistencia: "iQuántos embarazos no opuso la desconfianza de los ignorantes quando se emprendió reunir noticias exactas del estado de las escuelas de los lugares, de las rentas destinadas a este efecto y de otros elementos de la misma naturaleza precisos para formar el plan de una reforma!"124 Como explicaba la Miscelánea de comercio, artes y literatura las exacciones de cantidades excesivas y desproporcionadas a la capacidad de los contribuyentes, debidas al nuevo sistema de hacienda, no solo hizo que los municipios identificaran constitución con contribución sino que también ocultaran o falsearan la información solicitada por miedo a tener que pagar más. ${ }^{125}$

La precipitación tampoco ayudó. La circular ordenaba que en el plazo de tres meses se enviasen dichos informes a la secretaría de la Gobernación. En Valencia la circular la recibió el conde de Almodóvar; el 6 de junio de 1820 la remitió al alcalde y ayuntamiento de Valencia. Éste a su vez, la reenvió al arzobispo Veremundo Arias, que al no poder cumplirla se la envió a Vicente María Vergara, presidente de la Sociedad económica de amigos país de Valencia. El 31 de julio, la

122 Actas de la diputación de Valencia, 10 de octubre de 1822, pp. 28v-29r y v., Archivo de la diputación de Valencia.

123 Memoria leida a las Cortes por el encargado del Despacho de la secretaría de gobernación de la península, Diario de sesiones, apéndice segundo al núm. 7, 4 de marzo de 1821, pp. 85-105.

124 Expediente sobre la proposición hecha por Francisco Javier Aspiroz, intendente del reino de Valencia sobre la instrucción y mejora del método de educación y enseñanza en las escuelas de primeras letras, Archivo histórico nacional, sección Consejos, legajo 12004, exp. 56, p. 6.

125 Miscelánea de comercio, artes y literatura, núm. 58, lunes 13 de marzo de 1820. 
comisión nombrada por la Sociedad económica -Juan Bautista Pla y Joaquín Sáez de Quintillana- presentó terminado el informe. Se excusará, no obstante, porque hubiera querido que fuese más completo, pero "aislada de la perentoriedad, del culpable silencio de la mayor parte de los maestros de las referidas escuelas, que no han respondido a los oficios que se les han pasado... confiesa que habrá quedado quizá corta, en el informe que presenta." La manera en la que unos y otros van desembarazándose del asunto indica la dificultad que entrañaba. Los pocos datos que recoge el informe de la Sociedad económica dan idea del abandono de la instrucción primaria así como la falta de recursos materiales y personales. La mayor parte de los maestros no eran titulados. La Sociedad proponía disminuir el número de escuelas por falta de rentas, nombrar maestros aprobados por el gobierno y plantificar el método que se aprobase para evitar "los espiritus de partido" y que se igualaran las primeras ideas, "lo cual es tan necesario en el día para la consolidación del nuevo sistema de gobierno". ${ }^{126}$

El 10 de septiembre de 1820 y el 6 de noviembre de 1821,127 se reitera la petición de estos estados acompañando unos modelos para cumplimentar, a fin de facilitar tanto la elaboración de los informes como las estadísticas generales. Pero nuevamente muchas provincias no cumplieron y otras van enviando la documentación a destiempo. El ministerio no obstante, con la información de que disponía elaborará unas observaciones de las que cabe concluir, como de la memoria que presentara a las Cortes en 1821, que los problemas fundamentales eran la falta de maestros titulados y su dotación. ${ }^{128}$ La diputación de Valencia nombró una comisión de enseñanza pública -los diputados provinciales Ten, Hernández y Cortés- que se encargó de reunir todas las noticias que hubieren remitido los pueblos de la provincia. Con esta información proponían el establecimiento de escuelas allí donde no había. Tal fue el caso de Segorbe de la que se dio cuenta a la Diputación "del escandaloso abandono en que estaban las escuelas de primeras letras de la ciudad de Segorbe como resultaba del expediente general en el estado remitido por su Ayuntamiento a consecuencia de las reales órdenes de 29 de mayo y 20 de diciembre de 1820, circuladas por el Gefe Político" y se resolvió oficiar al ayuntamiento para que propusiera dentro el término preciso de 15 días, arbitrio con que establecer dos maestros de primeras letras, designando el local que tuviere para ambas escuelas o que lo pidiera con arreglo al art. 128 del decreto de 29 de junio de 1821 .

Los sueldos de los maestros dependian fundamentalmente de los propios de los pueblos, aunque no solamente -también de temporalidades, obras pías, pagados por consulados, sociedades y prelados, repartimiento vecinal, prestaciones voluntarias, mensualidades de las familias de niños...- ${ }^{129}$ de ahí que

126 Catálogo de escuelas de primeras letras en Valencia, 1820, caja 65 legajo III, sig. 2, la circular en caja 65 legajo III sig. 4, Archivo de la Real Sociedad Económica de Amigos del País de Valencia.

127 Orden de 6 de noviembre de 1821 recordando el cumplimiento de dos circulares fechas 29 de mayo y 20 de septiembre de 1820 pidiendo estado de las escuelas y establecimientos literarios de las provincias.

128 Observaciones generales sobre el ramo de la educación primaria, sacadas de los estados y de los pliegos trimestrales que han remitido los Gefes politicos de las Provincias que a continuación se expresan. Archivo del Congreso de los Diputados, legajo 77, núm. 142.

129 Memoria leida a las Cortes por el encargado del Despacho de la secretaría de gobernación de la península, apéndice segundo al núm. 7, 4 de marzo de 1821 
variaran en función de las posibilidades de la riqueza y número de habitantes de cada localidad.

Las rentas de propios de los municipios habian disminuido ostensiblemente con las reformas liberales. Los pueblos reclamarán se les permita dotar a los maestros con cargo a las rentas procedentes de arrendamientos de los monopolios que el liberalismo habia suprimido. Gran parte de los municipios valencianos manifestarian sus quejas en este sentido porque "los fondos de propios procedian del arriendo de la tienda, panaderia, taberna, carnicería, peso y medida de los que en el día carecen por la libertad; que por ello faltan fondos para pagar al maestro de primeras letras, maestra de niñas...; que la libertad de la venta es perjudicial". 130 Pero una y otra vez la diputación les negará esta posibilidad "por estar en contra del actual sistema". Debían proponer otros arbitrios que no gravaran los géneros de consumo ni impidiesen la libertad de tráfico interior.

Algunos maestros vieron reducida además su dotación al negarse a satisfacer el señor territorial la parte a la que se había comprometido, por no percibir sus rentas señoriales. Los maestros recurren a la diputación para que fuera el ayuntamiento quien sufragara la renta que habian dejado de percibir. De esta forma, Manuel Lauder maestro de Alcudia de Carlet acudió a la diputación porque "su salario está reducido a 20 libras, habiendo ya cesado el conde de la Alcudia en suministrarle 40 libras con que le socorría por via de limosna por cuya razón recurre pidiendo se le aumenten 80 libras más para poderse dedicar con todo esmero a la enseñanza y debiendo ser satisfechas del caudal de propios". El informe del ayuntamiento sería favorable a la demanda del maestro pero "sin que pueda exigir luego otros derechos". ${ }^{131}$ Agustín Barrachina maestro de Benimamet informaba de que "por haber cesado de satisfacerse el tercio-diezmo al monasterio de San Miguel de los Reyes, no paga tampoco 3 reales diarios que suministraba a los maestros y se ven reducidos a solo pasar de un real, por lo que pide se haga un reparto entre los que dejaron de satisfacer el tercio-diezmo ${ }^{132}$. El ayuntamiento informó que aunque efectivamente el Monasterio de San Miguel de los Reyes consignó al maestro 3 reales diarios y 2 reales a la maestra y que así se había verificado hasta el dia, parecía justo "que dicho monasterio continúe pagando las dotaciones que asignó, pues que el ayuntamiento no tiene que ver en que se le hayan suprimido los pagos de señorío porque en este caso tiene el monasterio su acción expedita para repetir donde le convenga, pero debe cumplir la contrata que hizo". ${ }^{133}$ Habiendo oído al prior, el comisionado provincial del

130 Archivo de la diputación de Valencia, libro de registro de entradas y salidas de expedientes, Poliñà, 11 de octubre de 1820, p. 52, vol. 2; también lo solicitaron el Real de Montroy, 1820, p. 9 vol. 1, Albuixech porque el maestro Francisco Izquierdo no cobra porque están suprimidas los puestos públicos, p. 37, vol. 1; Liria deja de pagar algunas cargas, p. 55, vol. 1.

131 Archivo de la diputación de Valencia, libro de registro de entradas y salidas de expedientes, vol. 1, 19 de julio de 1820, fol. 89 v. y vol. 2, p. 38.

132 Archivo de la diputación de Valencia, libro de registro de entradas y salidas de expedientes, vol. 2, 4 de octubre de 1820 , p. 49 v.

133 Archivo de la diputación de Valencia, libro de registro de entradas y salidas de expedientes, 15 de nov. de 1820, fol. 117v, vol. 2. 
crédito publico envió su informe ${ }^{134}$ de acuerdo con el cual, finalmente la diputación resolvió. Con el fin de que no faltasen maestros,

... que por este año proceda al reparto entre vecinos y terratenientes de la cantidad de 1.825 reales bajo las mismas reglas y con las propias formalidades que están prevenidas para el de la contribución general, con cuya suma hará el pago al maestro de primeras letras de 1.095 reales y a la maestra de 730 que son los que respectivamente les corresponden según los salarios que han disfrutado hasta ahora debiendo llevar la debida cuenta y razón lo mismo que de los demás fondos de propios; y se encarga a dicha corporación que sin demora y por medio del jefe político solicite del gobierno la continuación por el crédito público del honorario que el monasterio de San Miguel de los Reyes satisfacía a dichos maestros.

Esta resolución era interina a falta de lo que resolvieran las Cortes. ${ }^{135}$

Antonio Marques y Francisca Estors maestros de Almedijar denunciaron que percibian 50 libras del señor territorial, que ya no les pagaba porque se le negaba el pago de los derechos de señorío y pidieron a la diputación se hicieran cargo los vecinos. El ayuntamiento entendió que cuando se contrató a estos maestros no se contó con el tanto que el señor abonaba y por tal motivo no era responsabilidad del pueblo. ${ }^{136}$

La diputación debía encargarse de que el ayuntamiento buscara arbitrios si carecía de propios. Los repartos vecinales eran uno de los últimos recursos admitidos en la Constitución. El procedimiento para que fuera admisible es lento. Veamos el ejemplo de la villa de Otos.

La justicia y ayuntamiento de la baronía de Otos informan a la diputación de que por reglamento le fueron señalados 830 reales para los gastos de salarios. Esta cantidad se obtenia por reparto entre los vecinos y terratenientes. Solicitaban se aumentase dicha cantidad hasta 3.280 reales para pagar: al maestro de primeras letras 600 reales, al secretario 500, para el que cuida el reloj 180, para el portero del ayuntamiento 400, para fiestas votivas 300, para el predicador de cuaresma, 300: y para gastos extraordinarios 1.000 reales. La diputación pide informe al contador de propios sobre tal instancia. ${ }^{137} \mathrm{El}$ contador consideró que eran justas e indispensables las dotaciones señaladas y solo le parecía excesiva la de 1.000 reales para gastos extraordinarios; propone reducirla a 500 y así el reparto se rebajaría a 2.780 reales. Se pide al ayuntamiento que remita testimonio de su riqueza y número de vecinos, así como de las circunstancias que inducen la necesidad de las dotaciones que propone, debiendo el sindico emitir su dictamen por

134 Archivo de la diputación de Valencia, libro de registro de entradas y salidas de expedientes, 8 de febrero de 1821, II, p. 214.

135 Archivo de la diputación de Valencia, libro de registro de entradas y salidas de expedientes, 5 de abril de 1821 , p. 30, vol. 3, un año después se desamortizaría. Sobre la junta de crédito público, véase Pilar Toboso Sánchez, "La junta de crédito público en el trienio liberal", Revista de estudios politicos (Nueva época), 93 (julio-sep. 1996), 401-413.

136 Archivo de la diputación de Valencia, libro de registro de entradas y salidas de expedientes, vol. II, 1820, p. 34.

137 Archivo de la diputación de Valencia, libro de registro de entradas y salidas de expedientes, vol I, 26 de abril de 1820, fol. 7 v. 
separado, para acordar la providencia que corresponda. El 12 de agosto de 1820 el ayuntamiento devuelve las diligencias con el parecer de los síndicos y la diputación acuerda que:

...teniéndose en consideración por una parte que por falta de propios y arbitrios concedió a este pueblo, el extinguido consejo de Castilla, el arbitrio de un reparto entre vecinos y terratenientes de 830 reales de vellón en virtud de decreto de 6 de abril de 1806 para acudir a los gastos de salarios, veredas y demás y por otra que esta cantidad no es suficiente en mucho para los más precisos y urgentes, quales son el de que se establezca escuela de primeras letras que hasta ahora no ha habido, se dote competentemente al secretario de ayuntamiento, al portero del mismo y otros, y teniendo igualmente presente que la relación de estos pagos es tan urgente que no admite dilación por lo abandonada que se haya la primera educación de los niños recomendada eficazmente al cuidado de esta corporación, en uso de las facultades concedidas por el artículo 322 de la constitución política de la monarquía española se autoriza al ayuntamiento constitucional de la villa de Otos para que desde luego se proceda al reparto de 2780 reales entre vecinos y terratenientes... hasta que las Cortes a quien se consulte resuelvan en la primera legislatura lo que tengan por conveniente. ${ }^{138}$

La diputación provincial remite la resolución al secretario de despacho que lo presenta a las Cortes. Se pasa a la comisión de diputaciones provinciales ${ }^{139}$ que resolvió positivamente y devuelto a las Cortes, finalmente aprobarán el dictamen permitiendo el reparto. ${ }^{140}$

Conforme a estas disposiciones para la ciudad de Valencia la comisión de fomento de la diputación provincial presentó un proyecto de reglamento para establecer escuelas de primera enseñanza en esta ciudad, con arreglo al decreto de Cortes de 29 de junio de 1822 y quedó aprobado bajo las bases siguientes:

1. Se crearán 16 escuelas de enseñanza primaria; las doce primeras para leer, escribir, y contar, instruirse en los dogmas de la religión y obligaciones civiles del hombre y las cuatro segundas para aritmética, principios elementales de geometría y dibujo, necesarios o aplicado a las artes y oficios.

2. Las dotaciones para los maestros de primera clase serán de 4.000 reales de vellón y 5.000 para las segundas.

3. Dentro de un mes todos los Maestros deberán obtener título de aprobación, prohibiéndose toda enseñanza pública que no sea del plan establecido.

4. Las dotaciones se cargarán al presupuesto de gastos del Ayuntamiento de esta ciudad.

138 Archivo de la diputación de Valencia, libro de registro de entradas y salidas de expedientes, vol I, 31 de julio de 1820, fol. 105.

139 Diario de sesiones, 9 de marzo de 1821, p. 3.

140 Archivo de la diputación de Valencia, libro de registro de entradas y salidas de expedientes, núm. 82,7 de mayo de 1822 , p. 1230. También villa de Dolores, p. 13 v, vol. 3, 29 de marzo de 1821. 
5. Las diez escuelas de niñas se costearán también de los mismos fondos, dotandose las maestras con 4.000 reales.

6. Se permitirá la regalía o aldeada de $8 \mathrm{r}$. mensuales a los maestros de la primera clase y 12 a los de la segunda. ${ }^{141}$

Pero las circunstancias no permitirán llevarlo adelante.

\section{CONCLUSIÓN}

El esfuerzo legislativo iniciado en la etapa gaditana para escolarizar a niños y niñas, se continuará durante el Trienio liberal. Se alcanzará la primera ley de instrucción pública en 1821, que se desarrollará interinamente para poner en práctica la enseñanza primaria, en 1822. No serán los contenidos de esta enseñanza los mismos para ambos sexos pues se tendrá en cuenta los roles que debian jugar en la sociedad en cuanto fuesen adultos. Se quiere alfabetizar a todos, pero mientras a los niños se les explicará y hará aprender de memoria la Constitución, a las niñas se las aplicará principalmente en las labores domésticas. No se crea una escuela para enseñar a los maestros, pero se les exigirán unos mínimos de conocimientos así como su adhesión a la Constitución para poder aprobar el examen que les capacite para el ejercicio de su profesión.

En los primeros años, 1820 y principios de 1821, todos los expedientes de los pueblos se referirán a la necesidad de tener o mantener una escuela con un maestro dotado convenientemente. También aluden a las maestras la mayoría de los ayuntamientos, aunque proponiendo un sueldo inferior al de los maestros. Pero todos coinciden en la necesidad de recursos económicos. Poco a poco las dotaciones que prometen en un principio, se van convirtiendo en una carga excesiva para los vecinos hasta el punto de comenzar a solicitar a sus diputaciones recortes en los sueldos de los docentes, aunque nunca serán aceptados. ${ }^{142} \mathrm{El}$ esfuerzo económico es enorme y no todos pueden afrontarlo, de ahí que se vayan disponiendo nuevos medios y arbitrios para aplicar a la enseñanza pública. Entre otros, se aprobará el solicitar de los padres de los niños una pequeña cantidad y hacer pagar a los maestros por la expedición de sus títulos. La comisión de instrucción pública expresaba que lo hacía "con mucho dolor pero obligado por la imperiosa ley de la necesidad, pues no encuentra recursos para llevar a cabo el establecimiento de la enseñanza y peor seria carecer de ella que hacerla un poco más costosa". ${ }^{143}$ Las escuelas no serán ya gratuitas.

Todos estos proyectos quedaron en el olvido el 1 de octubre de 1823. La adhesión a la Constitución será sustituida por la adhesión al rey y al régimen absolutista y los juicios de purificación impedirán continuar o acceder al

141 Actas de la diputación de Valencia, 27 de febrero de 1823, p. 43 r y v., Archivo de la diputación de Valencia.

142 Archivo de la diputación de Valencia, libro de registro de entradas y salidas de expedientes, 22 de marzo, 1821, p. 289, Carpesa.

143 Decreto de 29 de junio de 1822, Colección de decretos y órdenes generales que han expedido las Cortes desde $1^{\circ}$ de marxo hasta 30 de junio de 1822, Tomo IX, p. 554, Madrid, Imprenta nacional, 1822. 
magisterio a aquéllos con informes negativos a veces referidos a la adhesión manifestada a la Constitución. ${ }^{144}$

Fecha de envio / Submission date: 12/02/2020

Fecha de aceptación / Acceptance date: 10/04/2020

${ }^{144}$ Fernando Vicente Jara, La enseñanza primaria en Murcia en el siglo XIX (1800-1857), Consejería de cultura, educación y turismo, Murcia, 1989, p. 148. 